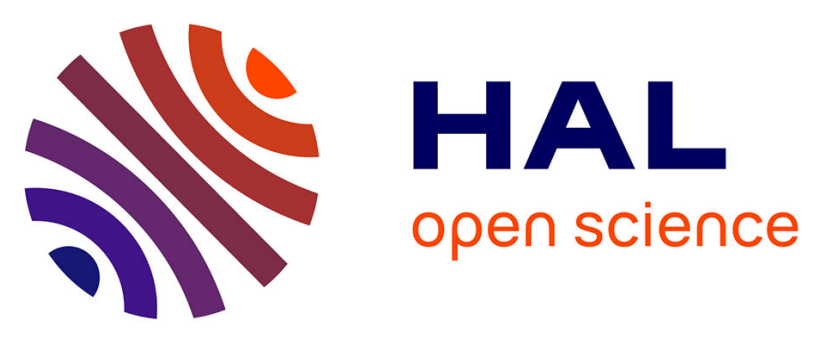

\title{
Thermodynamic study of binary systems containing sulphur dioxide and nitric oxide: measurements and modelling
}

Benoit Creton, Carlos Nieto-Draghi, Theodorus de Bruin, Véronique Lachet, Elise El Ahmar, Alain Valtz, Christophe Coquelet, Silvia Lasala, Romain Privat, Jean-Noël Jaubert

\section{To cite this version:}

Benoit Creton, Carlos Nieto-Draghi, Theodorus de Bruin, Véronique Lachet, Elise El Ahmar, et al.. Thermodynamic study of binary systems containing sulphur dioxide and nitric oxide: measurements and modelling. Fluid Phase Equilibria, 2018, 461, pp.84-100. 10.1016/j.fluid.2017.12.036 . hal01701205

\section{HAL Id: hal-01701205}

https://hal-mines-paristech.archives-ouvertes.fr/hal-01701205

Submitted on 5 Feb 2018

HAL is a multi-disciplinary open access archive for the deposit and dissemination of scientific research documents, whether they are published or not. The documents may come from teaching and research institutions in France or abroad, or from public or private research centers.
L'archive ouverte pluridisciplinaire HAL, est destinée au dépôt et à la diffusion de documents scientifiques de niveau recherche, publiés ou non, émanant des établissements d'enseignement et de recherche français ou étrangers, des laboratoires publics ou privés. 


\title{
Thermodynamic study of binary systems containing sulphur dioxide and nitric oxide: measurements and modelling.
}

\author{
Benoit Creton*, Carlos Nieto-Draghi, Theodorus de Bruin, \\ IFP Energies nouvelles, 1 et 4 avenue de Bois-Préau, 92852 Rueil-Malmaison, France. \\ Véronique Lachet \\ IFP Energies nouvelles, 1 et 4 avenue de Bois-Préau, 92852 Rueil-Malmaison, France. \\ Laboratoire de Chimie Physique, Université Paris-Sud, UMR 8000 CNRS, Orsay, France. \\ Elise El Ahmar, Alain Valtz, Christophe Coquelet, \\ MINES ParisTech, PSL - Research University, CTP - Centre Thermodynamique des \\ Procédés, 35 rue Saint Honoré, 77300 Fontainebleau, France. \\ Silvia Lasala, Romain Privat, Jean-Noël Jaubert \\ Université de Lorraine, Ecole Nationale Supérieure des Industries Chimiques, Laboratoire \\ Réactions et Génie des Procédés (UMR CNRS 7274), 1 rue Grandville, 54000 Nancy, \\ France.
}

\begin{abstract}
In this study, the thermodynamic behaviour of $\mathrm{NO}+\mathrm{SO}_{2}$ mixtures has been investigated by means of molecular simulation, experiment and equation of state modelling. Quantum chemical calculation were performed to investigate possible chemical reactions between $\mathrm{NO}$ and $\mathrm{SO}_{2}$. Molecular simulations were based on Monte Carlo and Molecular Dynamics techniques using force fields available in the literature. Validation of simulated vapour liquid data for $\mathrm{NO}+\mathrm{SO}_{2}$ binary mixtures was performed on the basis of proposed new experimental data, and new sets of parameters were optimized for the PPR78 EoS. We then moved our focus on the solubility of some gases $\left(\mathrm{SO}_{x}, \mathrm{NO}_{x}, \mathrm{CO}_{2}, \mathrm{O}_{2}, \mathrm{~N}_{2}\right)$ in water and brines studied by molecular simulations. We first compared performances of some combinations of salt and water intermolecular potentials in terms of
\end{abstract}

\footnotetext{
*Corresponding author: benoit.creton@ifpen.fr
} 
density and osmotic pressure predictions. We then studied the evolution of Henry constant values for gases in brines considering various salt concentrations and temperatures.

Keywords:

Sulphur dioxide, Nitric oxide, Brine, Molecular simulation, Experiment, EoS modelling 


\section{SYMBOLS AND ACRONYMS}

\begin{tabular}{|c|c|}
\hline$\gamma-\phi$ & Activity-fugacity \\
\hline $\mathrm{BE}$ & Bonding energy \\
\hline $\mathrm{CCS}$ & Carbon Dioxide Capture and Storage \\
\hline CoM & Centre of mass \\
\hline $\mathrm{E}_{\text {elec }}$ & Electronic energy \\
\hline EoS & Equation of State \\
\hline EPM2 & Rescaled Elementary Physical Model \\
\hline$f$ & Fugacity \\
\hline $\mathrm{GC}$ & Gas Chromatograph \\
\hline GHGs & Greenhouse Gases \\
\hline HMCMD & Hybrid Monte Carlo Molecular Dynamics \\
\hline IRC & Intrinsic Reaction Coordinate \\
\hline$K_{H}$ & Henry constant \\
\hline$k_{i j}$ & Binary interaction parameters \\
\hline$K_{S}$ & Sechenov constant \\
\hline LJ & Lennard-Jones \\
\hline $\mathrm{m}$ & Molality \\
\hline MAE & Mean Absolute Error \\
\hline $\mathrm{MC}$ & Monte Carlo \\
\hline MD & Molecular Dynamics \\
\hline$N$ & Number of particles \\
\hline$N p T$ & Isobaric-isothermal ensemble \\
\hline$P$ & Pressure \\
\hline PR & Peng-Robinson \\
\hline $\mathrm{P}^{\text {sat }}$ & Vapour pressure \\
\hline RMS & Root Mean Square \\
\hline $\mathrm{SPC} / \mathrm{E}$ & Extended Simple Point Charge \\
\hline$T$ & Temperature \\
\hline TCD & Thermal conductivity detector \\
\hline TIP4P /2005 & Transferable Intermolecular Potential with 4 sites \\
\hline$U_{\text {disp }}$ & Dispersion interactions \\
\hline$U_{\text {elec }}$ & Electrostatic energy \\
\hline$U_{\text {rep }}$ & Repulsion interactions \\
\hline VL & Vapour liquid \\
\hline $\mathrm{ZPE}$ & Zero-point energy \\
\hline
\end{tabular}




\section{Introduction}

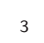

4

5

Facing the problem of global warming, many industrialized countries recently agreed in reducing their greenhouse gases (GHGs) emissions [1]. Industrial activities involving the combustion of fossil resources are responsible for a large part of the human induced carbon dioxide $\left(\mathrm{CO}_{2}\right)$ emissions. Various options have been already proven technically feasible to regulate anthropogenic $\mathrm{CO}_{2}$ emissions to the atmosphere, and among them the carbon dioxide capture and storage (CCS) appears as a transitional key technology 2]. $\mathrm{CO}_{2}$ can be stored in depleted geological reservoirs or deep saline aquifers [3, 4, 5]. Due to its origin and despite performed treatments, the injected $\mathrm{CO}_{2}$ stream may contain small amounts of associated gaseous components such as $\mathrm{O}_{2}, \mathrm{~N}_{2}, \mathrm{SO}_{x}, \mathrm{NO}_{x}$, as well as traces of noble gases [5, 6]. Varying amounts of such gas impurities in the $\mathrm{CO}_{2}$ stream may induce more or less pronounced changes of the gas mixture properties, thus impacting the design and operation of CCS industrial units $\underline{6}$, 7, 8, 9]. Additionally, $\mathrm{CO}_{2}$ and associated gases may react with subsurface components (brine, reservoir rocks, cap-rocks...) under certain salinity values, temperature and pressure conditions, affecting the long-term behaviour of the $\mathrm{CO}_{2}$ containing mixture injected within storage sites.

The use of reactive-transport codes to investigate various scenarios is of upmost interest [10, 11, 12]. In most of the geochemical codes, chemical reactions and their equilibria are related to classical mass action laws, and water-gas equilibria are generally treated using a dissymmetrical approach $\gamma-\phi$ (i.e., activityfugacity) wherein the Henry constant $\left(K_{H}\right)$ of gas species is a key property. Note that these calculations involve the use of an equation of state (EoS), and the Peng-Robinson (PR) EoS is usually used in geochemical codes [13]. EoS settings, more precisely binary interaction parameters $\left(k_{i j}\right)$, are determined from regressions on available experimental data. The precise knowledge of the thermodynamics behaviour for binary mixtures containing: (i) $\mathrm{CO}_{2}$ and impurities (ii) and impurities with one another, in CCS operation conditions - temperatures ranging from $218 \mathrm{~K}$ to $423 \mathrm{~K}$ and pressures up to $50 \mathrm{MPa}$ [14], is necessary 
to make accurate predictions using reactive-transport codes. Recent literature reviews have highlighted a wide disparity in the experimental knowledge for such binary gas mixtures [14, 15, 16, 17]. For instance, binary systems containing $\mathrm{CO}_{2}$ and oxygen $\left(\mathrm{O}_{2}\right)$ have been largely studied while there is only scarce information on binary systems containing sulphur dioxide $\left(\mathrm{SO}_{2}\right)$ and nitric oxide (NO).

Molecular simulation techniques have been proven as cost-efficient alternatives to experimental measurements, especially when hazardous compounds and/or extreme pressure or temperature conditions are considered. These last years, we have devoted much effort to the use of molecular simulation techniques to predict vapour-liquid (VL) equilibria and transport properties for binary mixtures containing $\mathrm{CO}_{2}$ and impurities and impurities with one another, within the different CCS stages [6, 7], 17, 18, 19, 20, 21]. Lachet et al. and Creton et al. have generated using Monte Carlo (MC) molecular simulations, data for $\mathrm{CO}_{2}+\mathrm{SO}_{2}$ binary mixtures for temperatures ranging from $263 \mathrm{~K}$ to $333 \mathrm{~K}$ and pressures up to $9 \mathrm{MPa}$ [6, 19]. Lachet et al. and Bourasseau et al. have studied using Gibbs ensemble MC coupled with the reactive ensemble, the behaviour of $\mathrm{CO}_{2}+\mathrm{NO}_{x}$ mixtures [18, 21]. Simulated data were obtained for $\mathrm{CO}_{2}+\mathrm{N}_{2} \mathrm{O}$ binary mixtures and $\mathrm{CO}_{2}+\mathrm{NO}$ binary mixtures for temperatures ranging from $253 \mathrm{~K}$ to $293 \mathrm{~K}$ and pressures up to $11 \mathrm{MPa}$, and considering the chemical equilibrium $2 \mathrm{NO} \rightleftharpoons \mathrm{N}_{2} \mathrm{O}_{2}$ [21]. Authors have demonstrated that for CCS operation conditions of temperatures, only the monomer (NO) form exists. Bourasseau et al. have studied the $\mathrm{CO}_{2}+\mathrm{NO}_{2} / \mathrm{N}_{2} \mathrm{O}_{4}$ reacting system considering the equilibrium $2 \mathrm{NO}_{2} \rightleftharpoons \mathrm{N}_{2} \mathrm{O}_{4}$, for temperatures ranging from $300 \mathrm{~K}$ to 330 $\mathrm{K}$ and pressures up to $7 \mathrm{MPa}$ [18]. Some simulated data were also proposed for $\mathrm{CO}_{2}+$ Ar binary mixtures for temperatures ranging from $248 \mathrm{~K}$ to $288 \mathrm{~K}$ and pressures up to $13 \mathrm{MPa}$ [6]. Creton et al. also reported simulated data for (i) $\mathrm{CO}_{2}+\mathrm{O}_{2}$ binary mixtures for temperatures ranging from $233 \mathrm{~K}$ to $273 \mathrm{~K}$ and pressures up to $12 \mathrm{MPa}$, (ii) and $\mathrm{CO}_{2}+\mathrm{N}_{2}$ binary mixtures for temperatures ranging from $220 \mathrm{~K}$ to $273 \mathrm{~K}$ and pressures up to $17 \mathrm{MPa}$ [6]. Simulated phase envelopes have been also proposed for binary systems of impurities with one 
another, and $\mathrm{El}$ Ahmar et al. studied $\mathrm{SO}_{2}+\mathrm{N}_{2}$ binary mixtures and $\mathrm{SO}_{2}+\mathrm{O}_{2}$ binary mixtures for temperatures ranging from $323 \mathrm{~K}$ to $413 \mathrm{~K}$ and pressures up to $85 \mathrm{MPa}$ [20].

In the present work, we first propose new insights for $\mathrm{SO}_{2}+\mathrm{NO}$ binary systems by means of experimental and molecular simulation techniques. Afterwards, settings of an EoS are optimized on the basis of VL equilibrium data. New experimental VL equilibrium data are proposed and compared to data obtained with Monte Carlo molecular simulations for temperatures ranging from $273 \mathrm{~K}$ to $345 \mathrm{~K}$. Generated MC simulation data are used to optimize sets of parameters for a PR based EoS. We then propose a comparison of various combinations of intermolecular potentials to mimic brines behaviour using molecular simulation, and provide some simulated Henry constant values in water and in brines for a series of gases including $\mathrm{SO}_{2}$ and NO.

\section{Materials and methods}

\subsection{Materials, apparatus and experimental procedure}

Sulphur dioxide $\left(\mathrm{SO}_{2}\right.$, CAS number: 7446-09-5) and nitric oxide (NO, CAS number: 10102-43-9) were supplied by Air Liquide with a certified purity higher than 99.9 vol\% and 99 vol\%, respectively (Table 1). No additional purification was performed before use, except for careful degassing.

The apparatus was designed based on a "static-analytic method" and is similar to the one previously used for measurements of equilibrium properties of $\mathrm{CO}_{2}+\mathrm{NO}$ mixtures 22]. Two capillary ROLSI ${ }^{\circledR}$ samplers (Armines patents) 23] are available to sample liquid and vapour phases. The cell volume is about $30 \mathrm{ml}$ and it can be operated up to $473 \mathrm{~K}$. The equilibrium cell is made of a sapphire (aluminium oxide $\mathrm{Al}_{2} \mathrm{O}_{3}$ ) tube (maximum pressure $10 \mathrm{MPa}$ ) between two Hastelloy flanges. With the sapphire tube, we have the possibility to see the mixture at equilibrium conditions. A magnetic Hastelloy stirrer driven by an adjustable speed external system is placed inside the cell in order to speed up the reaching of the thermodynamic equilibrium. 
Table 1: Chemical sample. GC stands for gas chromatograph.

\begin{tabular}{ccccc}
\hline Chemical name & CAS number & Source & $\begin{array}{c}\text { Initial purity } \\
\text { (weight } \%)\end{array}$ & $\begin{array}{c}\text { Analysis } \\
\text { method }\end{array}$ \\
\hline $\begin{array}{c}\text { Sulphur dioxide } \\
\text { Nitric oxide }\end{array}$ & $\begin{array}{c}7446-09-5 \\
10102-43-9\end{array}$ & Air Liquid & $\geq 99.9$ & GC \\
& & & $\geq 99$ & GC \\
\hline
\end{tabular}

The sapphire cell is totally immersed in a liquid bath which keeps the temperature stable to $\pm 0.1 \mathrm{~K}$. The cell is equipped with two platinium probes in order to obtain a precise measure of the temperature $( \pm 0.02 \mathrm{~K})$. The pressure in the cell is measured by a pressure transducer with an accuracy of $\pm 6.10^{-4}$ $\mathrm{MPa}$. The pressure transducer and temperature probes are connected to a HP data acquisition unit (HP34970A). The HP data acquisition unit is connected to a computer through a RS232 interface. The sample extracted from the cell are sent to a gas chromatograph (GC) for compositional analysis. The used GC is the Shimadzu GC-2014 equipped with a thermal conductivity detector (TCD), which is calibrated for the studied compounds. The calibration of the TCD is made by introducing known pure component volumes with appropriate GC syringes. Accuracies regarding mole numbers are $\pm 1 \%$ for $\mathrm{NO}$ and $\pm 0.8 \%$ for $\mathrm{SO}_{2}$. The maximum standard uncertainty on liquid and vapour mole fractions (Umax $(\mathrm{x}, \mathrm{y}))$ is 0.004 . The HayeSep D (80/100 mesh $2 \mathrm{~m} \mathrm{X} \mathrm{1/8"} \mathrm{silcosteel} \mathrm{tube)}$ GC packed column is used.

\subsection{Classical thermodynamics modelling}

One of the objectives of this paper is to derive a thermodynamic model able to accurately correlate the VL equilibrium data acquired in this study. On account of its simplicity and accurateness, it was decided to use the PengRobinson equation of state with advanced mixing rules that combine the EoS with the residual part of an excess Helmholtz energy model, $a_{r e s}^{E, \gamma}$. For a mixture containing $N C$ components with known mole fractions $z_{i}$, such mixing rules 
write as follows [24, 25, 26]

$$
\left\{\begin{array}{l}
b_{m}=\sum_{i=1}^{N C} \sum_{j=1}^{N C} z_{i} z_{j} b_{i j}, \text { with } b_{i j}=\left(\frac{b_{i}^{1 / s}+b_{j}^{1 / s}}{2}\right)^{s} \\
\frac{a_{m}}{b_{m}}=\sum_{i=1}^{N C} z_{i} \frac{a_{i}}{b_{i}}+\frac{a_{r e s}^{E, \gamma}}{\Lambda}
\end{array}\right.
$$

As a general rule, exponent $s$ is set to a value lower or equal to 2. Parameter $\Lambda$ is a constant, and its value depends on the selected cubic EoS. The purecomponent parameters $a_{i}$ and $b_{i}$ are classically estimated from PR EoS by:

$$
\left\{\begin{array}{l}
X=[1+\sqrt[3]{4-2 \sqrt{2}}+\sqrt[3]{4+2 \sqrt{2}}]^{-1} \approx 0.25308 \\
b_{i}=\Omega_{b} \frac{R T_{c, i}}{P_{c, i}}, \text { with } \Omega_{b}=\frac{X}{X+3} \approx 0.077796 \\
a_{i}(T)=a_{c, i} \cdot \alpha_{i}(T), \text { with: } \\
a_{c, i}=\Omega_{a} \frac{R^{2} T_{c, i}^{2}}{P_{c, i}}, \text { and } \Omega_{a}=\frac{8(5 X+1)}{49-37 X} \approx 0.45723 \\
\alpha_{i}(T)=\left[1+\left(0.37464+1.54226 \omega_{i}-0.26992 \omega_{i}^{2}\right)\left(1-\sqrt{\frac{T}{T_{c, i}}}\right)\right]^{2}
\end{array}\right.
$$

The Soave $\alpha$-function incorporated in the original PR EoS model has been maintained as it retains a thermodynamically consistent behavior [27, 28, 29] in the whole temperature domain of interest for the two considered components (up to about $600 \mathrm{~K}$ for $\mathrm{NO}$ and $2000 \mathrm{~K}$ for $\mathrm{SO}_{2}$ ). The PR EoS was not volume-translated [30, 31] since such a translation does not affect VL equilibrium calculations.

Following our previous studies on binary systems involved in CCS processes [16, 32], it was first decided to correlate the available data with the PPR78 model [33, 34]. For such a model, exponent s in equation (11) must be set to unity and the activity coefficient model $\left(a^{E, \gamma}\right)$ is a one-parameter Van Laar expression:

$$
\frac{a_{r e s}^{E, \gamma}}{\Lambda}=\frac{1}{2} \cdot \frac{\sum_{i=1}^{N C} \sum_{j=1}^{N C} z_{i} z_{j} b_{i} b_{j} E_{i j}(T)}{\sum_{i=1}^{N C} z_{i} b_{i}}
$$


As required by equation (1), such an expression is a purely residual $a^{E}$ model (it does not contain a combinatorial part). Following the mixing rule derived for the PPR78 model, the unique $E_{12}$ parameter in equation (3) - needed to correlate the phase behavior of the $\mathrm{NO}+\mathrm{SO}_{2}$ binary system - was selected temperature-dependent through the following relation:

$$
E_{12}=A_{12} \cdot\left(\frac{298.15}{T}\right)^{\left(\frac{B_{12}}{A_{12}}-1\right)},
$$

where $A_{12}$ and $B_{12}$ are two adjustable parameters. In order to improve the quality of the correlation, the Van Laar $a^{E}$ model was subsequently replaced by the more sophisticated Wilson model. This second study was conducted because the $\mathrm{NO}+\mathrm{SO}_{2}$ mixture exhibits a type III phase behaviour and that such systems are known to be particularly difficult to correlate.

\subsection{Molecular simulation techniques}

The GIBBS Monte Carlo code 35] has been used to generate thermodynamic data for studied systems containing gaseous components and/or water and/or salts. VL equilibrium data were obtained with MC molecular simulations performed in the Gibbs $N p T$ - isobaric-isothermal - ensemble where the number of particles $(N)$, the total pressure $(P)$ and the temperature $(T)$ are constant [36, 37]. During these MC simulations, vapour and liquid phases are simultaneously considered in two distinct simulation boxes, without considering their interface. Transfers of particles between the two simulation boxes ensure the chemical equilibrium of the system. The sampling of the configurational space is ensured by different Monte Carlo moves, such as rigid body translations or rotations of molecules, and volume changes. The used MC moves and associated attempt probalities are as follows: rigid body translations (0.2975), rotations $(0.2975)$, volume changes $(0.0050)$, and transfers $(0.4000)$. For translation, rotation, and volume change moves, maximum amplitudes were adapted to reach acceptance rates of 0.4 . The studied systems contained in between 1000 and 2000 molecules depending on the vicinity of the critical point. For each MC 
simulation, the number of generated configurations ranged within $2.10^{8}$ and $2.10^{9}$ including the equilibration of the system and the production run.

In the case of strongly associated systems such as brines, the above mentioned MC moves are not efficient enough to sample the configurational part of the phase space, and reaching the equilibrium state may necessitate important computational resources. To improve the sampling efficiency, we performed Hybrid Monte Carlo Molecular Dynamics (HMCMD) simulations [38, 39]. An HMCMD move consists in letting the system evolves deterministically through the phase space using a short Molecular Dynamics (MD) run as a MC move, in addition to other usual moves. In contrast to MC simulations, MD simulations enable the exploration of the whole phase space (i.e. all possible values of positions and momenta) with collective motions of all particles at each time step. MD steps were performed using the NEWTON Molecular Dynamics code developed for flexible and rigid molecules [40]. Hereafter, a HMCMD move corresponds to $50 \mathrm{MD}$ steps with an adjustable MD time step so as to reach an average acceptance ratio of $c a$. 40\%. All details regarding the implementation and the combination of the GIBBS and NEWTON codes are given elsewhere [39].

Molecular Dynamics simulations were performed with the NEWTON code to generate osmotic pressure values following the method proposed by Luo and Roux [41]. It consists in introducing virtual walls in the simulation box to separate brine and pure water regions, only water molecules can move from one region to the other. Forces resulting from interactions of ions with the walls are handled by a harmonic potential (with a constant of $41.9 \mathrm{~kJ} \cdot \mathrm{mol}^{-1} . \AA^{-2}$ ). The walls are placed with a separation distance in agreement with the desired ionic concentration. Ions leaving the constraint zone feel a force in the opposite direction (normal to the wall) in order to maintain them inside the ionic region (between the walls). The total average force exerted by the ions to the walls is directly related to the osmotic pressure. MD simulations start with an equilibration period where the system is relaxed by means of a 1 ns run using the NPzzT ensemble $(\mathrm{Pzz}=0.1 \mathrm{MPa}$ and $\mathrm{T}=298.15 \mathrm{~K})$, relaxing the size of the simulation box in the $\mathrm{z}$ direction. During this equilibration period, the 
distance between walls is fixed in order to preserve the volume occupy by ions (i.e. the ionic concentration of the system). After this period the average box size in $\mathrm{z}$ direction is computed and the average Lz value is imposed to the system. Then, an additional 2 ns equilibrium simulation in the NVT ensemble (T $=298 \mathrm{~K})$ is performed and followed by a $5 \mathrm{~ns}$ production run. Three different simulation runs, starting from independent initial configurations, were used to produce average values of the osmotic pressure for each system. The orthorhombic simulation boxes are composed of about 3000 water molecules divided into two regions: one contains the brine and the other contains pure water, with the pure water region representing two thirds along the z-axis.

\subsection{Molecular models and force fields}

As described hereafter, only rigid body molecules are considered thus no intramolecular energy has been computed. The total potential energy of the systems is calculated as the sum of the two contributions: dispersion-repulsion interactions $\left(U_{\text {disp }}\right.$ and $\left.U_{\text {rep }}\right)$ and the electrostatic energy $\left(U_{\text {elec }}\right)$. A 12-6 LennardJones (LJ) potential (equation (5)) has been used to represent the dispersionrepulsion energy between two force centres $i$ and $j$ belonging to different molecules and separated by a distance $r_{i j}$. During MC and MD simulations, $U_{i j}$ interactions were evaluated using a spherical cut-off radius equal to half the size of the cubic simulation box, associated with standard long-range corrections.

$$
U_{i j}=U_{r e p}+U_{d i s p}=4 \epsilon_{i j}\left(\left(\frac{\sigma_{i j}}{r_{i j}}\right)^{12}-\left(\frac{\sigma_{i j}}{r_{i j}}\right)^{6}\right),
$$

where $\epsilon_{i j}$ and $\sigma_{i j}$ are the LJ parameters, and equations (6) and (7) present the Lorentz-Berthelot combining rules used to compute cross interaction parameters.

$$
\begin{gathered}
\epsilon_{i j}=\sqrt{\epsilon_{i} \epsilon_{j}}, \\
\sigma_{i j}=\frac{\sigma_{i}+\sigma_{j}}{2} .
\end{gathered}
$$


During both $\mathrm{MC}$ and MD simulations, $U_{\text {elec }}$ was computed from the Coulomb law (equation (8) ) and evaluated using the Ewald summation method with 7 vectors in each direction of the space and a gaussian width set to $2 \pi / L$, where $L$ is the length of the cubic simulation box.

$$
U_{\text {elec }}=\frac{1}{4 \pi \epsilon_{0}} \frac{q_{i} q_{j}}{r_{i j}},
$$

where $q_{i}$ and $q_{j}$ are two point charges belonging to different molecules and spaced by $r_{i j}$, and $\epsilon_{0}$ is the vacuum permittivity.

Values of $\epsilon_{i}, \sigma_{i}$, and $q_{i}$ parameters constitute the force field parameters. The GIBBS MC and the NEWTON MD simulation codes have both already been successfully used with intermolecular potentials listed in Table 2, and calculations have already shown good accuracy in the restitution of both equilibrium and/or transport properties for pure $\mathrm{SO}_{2}, \mathrm{NO}, \mathrm{CO}_{2}, \mathrm{~N}_{2}$, and $\mathrm{O}_{2}$ as well as some mixtures of these gases [6, 20, 21].

Force field parameters used to mimic $\mathrm{SO}_{2}, \mathrm{NO}, \mathrm{CO}_{2}, \mathrm{~N}_{2}$, and $\mathrm{O}_{2}$ are summarized in Table 2. The model developed by El Ahmar et al. has been used to mimic properties of sulphur dioxide [20]. The $\mathrm{SO}_{2}$ molecule is represented as follows: each atom of the molecule is a LJ centre, and the $\mathrm{S}-\mathrm{O}$ distance and the $\widehat{\mathrm{OSO}}$ angle are equal to $1.434 \AA$ and $119.50^{\circ}$, respectively. A negative point charge is located on each oxygen atoms, and $\mathrm{q}^{+}$a positive point charge is placed on the bisector of the $\widehat{\mathrm{OSO}}$ angle at $0.312 \AA$ from the sulphur atom, as illustrated in Table 2 The force field chosen to restitute molecular nitric oxide behavior was developed by Lachet et al. 21]. It consists of a single Lennard-Jones sphere. Note that this model well reproduces the variation of mole fraction of associated $\mathrm{N}_{2} \mathrm{O}_{2}$ as a function of temperature along the saturation line for the bulk liquid phase of the $2 \mathrm{NO} \rightleftharpoons \mathrm{N}_{2} \mathrm{O}_{2}$ system. The carbon dioxide has been extensively studied using molecular simulations, and the rigid version of the rescaled elementary physical model (EPM2) proposed by Harris and Yung [42] has shown that VL equilibrium data for pure $\mathrm{CO}_{2}$ are well reproduced. Each atom carries both a LJ centres and an electrostatic point charge, and the $\mathrm{C}-\mathrm{O}$ distance is 
Table 2: Force field parameters for the studied molecules.

\begin{tabular}{|c|c|c|c|c|c|c|}
\hline Molecule & & $\begin{array}{l}\text { Force } \\
\text { centre } \\
\text { r charge }\end{array}$ & $\sigma(\AA)$ & $\epsilon(\mathrm{K})$ & $\mathrm{q}(|\mathrm{e}|)$ & Ref. \\
\hline \multirow{3}{*}{\multicolumn{2}{|c|}{ O $\quad \mathrm{O}$}} & S & 3.5830 & 126.0800 & - & \multirow{3}{*}{20} \\
\hline & & $\mathrm{O}$ & 2.9900 & 46.4100 & -0.4140 & \\
\hline & & $\mathrm{q}^{+}$ & - & - & 0.8280 & \\
\hline NO & & $\mathrm{NO}$ & 3.4000 & 130.0000 & - & 21 \\
\hline \multirow{2}{*}{\multicolumn{2}{|c|}{$\mathrm{O} \quad \mathrm{C} \quad \mathrm{O}$}} & $\mathrm{O}$ & 3.0330 & 80.5070 & -0.3256 & \multirow{2}{*}{42} \\
\hline & & $\mathrm{C}$ & 2.7570 & 28.1290 & 0.6512 & \\
\hline \multirow{2}{*}{\multicolumn{2}{|c|}{$(\mathrm{N}) \cdot \mathrm{N}$}} & $\mathrm{N}$ & 3.3000 & 36.0000 & -0.5075 & \multirow{2}{*}{43} \\
\hline & & $\mathrm{q}^{+}$ & - & - & 1.0150 & \\
\hline \multirow{3}{*}{ O ${ }_{q^{-}}^{\mathrm{q}} \mathrm{O}$} & & $\mathrm{O}$ & 3.1062 & 43.1830 & - & \multirow{3}{*}{44,45} \\
\hline & & $\mathrm{q}^{-}$ & - & - & -2.1000 & \\
\hline & & $\mathrm{q}^{+}$ & - & - & 4.2000 & \\
\hline \multirow[b]{2}{*}{$\mathrm{H}$} & & $\mathrm{O}$ & 3.1655 & 78.1974 & -0.8476 & \multirow{2}{*}{ [46] } \\
\hline & $\mathrm{H}$ & $\mathrm{H}$ & - & - & 0.4238 & \\
\hline \multirow{3}{*}{$\mathrm{H}$} & \multirow{3}{*}{$\mathrm{H}$} & $\mathrm{O}$ & 3.1589 & 93.1990 & - & \multirow{3}{*}{47} \\
\hline & & $\mathrm{H}$ & - & - & 0.5564 & \\
\hline & & $\mathrm{q}^{-}$ & - & - & -1.1128 & \\
\hline
\end{tabular}


equal to $1.149 \AA$. It is important to mention that although the model has been developed using geometric combining rules, Nieto-Draghi et al. have shown that the combination of the EPM2 force field parameters with the Lorentz-Berthelot rules allows a good restitution of both thermodynamic and transport properties [48]. The molecular nitrogen has been represented using the force field developed by Delhommelle [43]. The two N atoms are separated by $1.098 \AA$ and each of them carries a LJ centre and a negative charge, a positive charge is placed on the centre of mass (CoM) of the molecule. On the basis of previous works, we have decided to mimic the oxygen behaviour using the Boutard et al. adaptation [45] of the Vrabec potential [44]. The two oxygen atoms carry each a LJ centre, and are separated by $1.210 \AA$. A positive electrostatic charge is located in between the two $\mathrm{O}$ atoms, and two negative charges are placed at $0.200 \AA$ on both sides of the CoM of the molecule along the $\mathrm{O}-\mathrm{O}$ bond.

Numerous potentials have been developed to mimic water properties with varied associated performances [49]. Among existing, we chose two widespread used models: the extended simple point charge (SPC/E) 46] and the transferable intermolecular potential with 4 sites (TIP4P/2005) [47], being aware of limitations of models involving rigid geometries and fixed electrostatic charges (i.e., non-polarizable models) [50, 51]. In the two selected models water is considered as a rigid body molecule, the oxygen atom of the molecule is a LJ centre and hydrogen atoms carry positive charges. The $\widehat{\mathrm{HOH}}$ angle is $109.47^{\circ}$ and $104.52^{\circ}$ for the SPC/E and TIP4P/2005 models, respectively. For the SPC/E model, a negative point charge is placed on the oxygen atom and the $\mathrm{O}-\mathrm{H}$ bond length is $1.000 \AA$. For the TIP4P/2005 model, a negative point charge is placed on the bisector of the $\widehat{\mathrm{HOH}}$ angle at $0.1546 \AA$ from the oxygen atom, and the $\mathrm{O}-\mathrm{H}$ bond length is $0.9572 \AA$. All details regarding force field parameters are summarized in Table 2. Sakamaki et al. compared performances of 12 non-polarizable water models including the SPC/E and TIP4P/2005 models to calculate, among others properties, VL equilibrium densities for temperatures from about $200 \mathrm{~K}$ to $650 \mathrm{~K}$ [52]. Recently, Vinš et al. performed a similar study focusing on the SPC/E and TIP4P/2005 models [53]. In this latter work, au- 
Table 3: Force field parameters considered for the sodium and chloride ions: OPLS, Whee, GoS, GoT, and Aqv refer to the parameter set proposed by Jorgensen et al., the parameter set proposed by Wheeler and Newman, the parameter set proposed by Goo et al. in combination with SPC/E, the parameter set proposed by Goo et al. in combination with TIP4P/2005, and the parameter set proposed by Aqqist, respectively.

\begin{tabular}{|c|c|c|c|c|}
\hline \multirow{2}{*}{ Label } & \multirow{2}{*}{ Ion } & \multicolumn{2}{|c|}{ LJ centre } & \multirow{2}{*}{ Ref. } \\
\hline & & $\sigma(\AA)$ & $\epsilon(\mathrm{K})$ & \\
\hline \multirow{2}{*}{ OPLS } & $\mathrm{Na}^{+}$ & 1.8974 & 808.7 & \multirow{2}{*}{54,55} \\
\hline & $\mathrm{Cl}^{-}$ & 4.4172 & 59.3 & \\
\hline \multirow{2}{*}{ Whee } & $\mathrm{Na}^{+}$ & 2.3500 & 55.3 & \multirow{2}{*}{56} \\
\hline & $\mathrm{Cl}^{-}$ & 4.4200 & 54.2 & \\
\hline \multirow{2}{*}{ GoS } & $\mathrm{Na}^{+}$ & 2.5864 & 50.3 & \multirow{4}{*}{57} \\
\hline & $\mathrm{Cl}^{-}$ & 4.4044 & 50.3 & \\
\hline \multirow{2}{*}{ GoT } & $\mathrm{Na}^{+}$ & 2.5931 & 42.2 & \\
\hline & $\mathrm{Cl}^{-}$ & 4.4111 & 42.2 & \\
\hline \multirow{2}{*}{ Aqv } & $\mathrm{Na}^{+}$ & 3.3304 & 1.4 & \multirow{2}{*}{54,55 , } \\
\hline & $\mathrm{Cl}^{-}$ & 4.4172 & 59.3 & \\
\hline
\end{tabular}

thors reported the following absolute deviations from experimental data: (i) at $250 \mathrm{~K}, 0.6 \%$ and $0.2 \%$ for the SPC/E and TIP4P/2005 models, respectively (ii) and at $500 \mathrm{~K}, 5.3 \%$ and $1.9 \%$ for the SPC/E and TIP4P/2005 models, respectively. We performed similar simulations and our results agreed with previous observations.

We have considered five sets of parameters for the sodium $\left(\mathrm{Na}^{+}\right)$and chloride $\left(\mathrm{Cl}^{-}\right)$ions in which both of them are represented as a sole LJ sphere with an associated positive $(+1|\mathrm{e}|)$ charge and negative $(-1|\mathrm{e}|)$ charge, respectively. Force field parameters used to mimic the sodium $\left(\mathrm{Na}^{+}\right)$and chloride $\left(\mathrm{Cl}^{-}\right)$ions are summarized in Table 3. Neyt et al. have computed densities for $\mathrm{NaCl}$ aqueous solutions at $298 \mathrm{~K}$ and $0.1 \mathrm{MPa}$ covering molalities up to $5.5 \mathrm{~mol} \cdot \mathrm{kg}^{-1}$, and demonstrated that the combination OPLS with TIP4P/2005 performs better than others such as Reif [59] with TIP4P/2005 [60, 61]. Orozco et al. compared some salt models combined with $\mathrm{SPC} / \mathrm{E}$ based water potentials for tempera- 
Table 4: Force field parameters considered for the calcium and chloride ions: Matt, GoS, GoT, Pred, and Aqv refer to the parameter set proposed by Matthews et al. and Jorgensen et al., the parameter set proposed by Goo et al. in combination with SPC/E, the parameter set proposed by Goo et al. in combination with TIP4P/2005, the parameter set proposed by Předota et al., and the parameter set proposed by Áqvist, respectively.

\begin{tabular}{|c|c|c|c|c|}
\hline \multirow{2}{*}{ Labels } & \multirow{2}{*}{ Ions } & \multicolumn{2}{|c|}{ LJ centre } & \multirow{2}{*}{ Ref. } \\
\hline & & $\sigma(\AA)$ & $\epsilon(\mathrm{K})$ & \\
\hline \multirow{2}{*}{ Matt } & $\mathrm{Ca}^{2+}$ & 2.7101 & 15.1 & \multirow{2}{*}{$54,55,64$} \\
\hline & $\mathrm{Cl}^{-}$ & 4.4172 & 59.3 & \\
\hline \multirow{2}{*}{ GoS } & $\mathrm{Ca}^{2+}$ & 1.5944 & 85.6 & \multirow{2}{*}{57,65} \\
\hline & $\mathrm{Cl}^{-}$ & 4.4044 & 50.3 & \\
\hline \multirow{2}{*}{ GoT } & $\mathrm{Ca}^{2+}$ & 1.6011 & 71.8 & \\
\hline & $\mathrm{Cl}^{-}$ & 4.4111 & 42.2 & \\
\hline \multirow{2}{*}{ Pred } & $\mathrm{Ca}^{2+}$ & 2.8950 & 50.3 & \multirow{2}{*}{ 66, 67 } \\
\hline & $\mathrm{Cl}^{-}$ & 4.4010 & 50.3 & \\
\hline \multirow{2}{*}{ Aqv } & $\mathrm{Ca}^{2+}$ & 2.4120 & 226.3 & \multirow{2}{*}{$54,55,58$} \\
\hline & $\mathrm{Cl}^{-}$ & 4.4172 & 59.3 & \\
\hline
\end{tabular}

tures and pressures up to $473 \mathrm{~K}$ and 1000 bar, respectively [62].

Five sets of parameters have been considered to describe calcium $\left(\mathrm{Ca}^{2+}\right)$ and chloride $\left(\mathrm{Cl}^{-}\right)$ions in which both of them are represented as a sole LJ sphere with an associated positive $(+2|\mathrm{e}|)$ charge and negative $(-1|\mathrm{e}|)$ charge, respectively. Force field parameters used to mimic the calcium $\left(\mathrm{Ca}^{2+}\right)$ and chloride $\left(\mathrm{Cl}^{-}\right)$ions are summarized in Table 4 . Note that Tsai et al. recently compared three sets of parameters including GoS and Aqv using two point charge based models (SPC and SPC/E) for water [63]. Performed comparisons have revealed that among the 6 considered combinaisons for water $-\mathrm{CaCl}_{2}$ models, SPC/E - Aqv gives the best density predictions at 373 and $473 \mathrm{~K}$ with, nevertheless, a significant underestimation of experimental denisties at 373 and $473 \mathrm{~K}$.

\subsection{Electronic structure calculations}

The electronic structure calculations were performed with the Gaussian 09 suite of programs [68]. All geometry optimizations were performed with the hy- 
brid M06 functional [69] using the spin unrestricted formalism (uM06), in combination with the $6-311+\mathrm{G}(\mathrm{d}, \mathrm{p})$ basis set. Systematic conformational searches were performed to identify the most stable structures. Standard convergence criteria were applied, i.e. $1 \times 10^{-8}$ Hartree for the electronic energy convergence, while for the geometry, convergences of 0.00045 and 0.00030 Hartree/Bohr for respectively the maximum and root mean square (RMS) forces were used, and threshold values of 0.0018 and 0.0012 Bohr for the maximum and RMS displacements, respectively. The character of the localized stationary points, i.e. minimum or first order transition state, on the potential energy surface was determined by calculating the Hessian matrix $\left(2^{\text {nd }}\right.$ derivative of the energy with respect to the atomic displacements). Furthermore, using intrinsic reaction coordinate (IRC) calculations it was verified that the transition state indeed connects reactants and products. Thermodynamic (enthalpic and entropic) contributions were calculated with the use of the partition functions within the harmonic oscillator and the perfect gaz approximation. Additionally, the resulting calculated vibrational frequencies have not been adjusted with an empirical correction factor. After the desired character of the stationary point was confirmed, the electronic wavefunction was subjected to a stability analysis to verify the presence of any singlet/triplet or doublet/quartet instabilities.

In this study, the uM06 functional in combination with the $6-311+\mathrm{G}(\mathrm{d}, \mathrm{p})$ basis set was selected, since it reproduces reasonably well the electronic state of the NO dimer. The NO dimer seems best described using a multi-reference method together with a large basis set [70], however, these methods can quickly become prohibitive for the systems investigated in this study, with respect to the needed computer resources.

\section{Results and discussion}

In this section, we present a series of new VL experimental data, together with modelling data obtained using both EoS and molecular simulation tools. We investigate $\mathrm{NO}+\mathrm{SO}_{2}$ systems using the three above mentioned techniques 
(experimental, EoS, molecular simulations). Concerning molecular simulation we first studied chemical reactions that may occur in the gas phase and we then generate simulated vapour liquid equilibrium data for a broad range of temperatures. We then move our focus on the solubility of different gases $\left(\mathrm{CO}_{2}\right.$ and associated gases such as $\mathrm{O}_{2}, \mathrm{~N}_{2}, \mathrm{SO}_{x}, \mathrm{NO}_{x}$ ) in brines. For this second study, simulation results are divided into two main parts devoted to the study of the solubility in water and in brines, respectively. The solubility is first expressed in terms of Henry constant values. In the case of sulphur dioxide solubility in water, we characterize deviations to the Henry's law with increasing pressure conditions. A similar solubility study is then proposed in the case of brines containing $\mathrm{NaCl}$ or $\mathrm{CaCl}_{2}$. We present a comparison of some combinations of salt and water potentials in terms of density and osmotic pressure predictions. We propose the generation of simulated Henry constant values for $\mathrm{CO}_{2}, \mathrm{SO}_{2}, \mathrm{NO}$, $\mathrm{O}_{2}$, and $\mathrm{N}_{2}$ in brines considering various salt concentrations and temperatures.

\subsection{Investigation of chemical reactions within $\mathrm{NO}+\mathrm{SO}_{2}$ systems}

Before studying phase equilibrium in $\mathrm{NO}+\mathrm{SO}_{2}$ systems, we first investigate the stability of such mixtures by means of electronic structure calculations. Such calculations have been performed in the gas phase, considering the following chemical reaction: $\mathrm{SO}_{2}+2 \mathrm{NO} \rightleftharpoons \mathrm{SO}_{3}+\mathrm{N}_{2} \mathrm{O}$. With the use of the applied method (see section 2.5) the singlet spin ${ }^{1} A_{1}$ is calculated to be slightly more stable than the ${ }^{3} B_{2}$ triplet state by $0.99 \mathrm{kcal} . \mathrm{mol}^{-1}$, which is in accordance with the CASSCF results of Sayos et al. 71], see Table 5. However, it appears that the calculated singlet electronic structure has an instability, while the triplet state is stable under the considered perturbations. We therefore have taken the triplet state as the most stable electronic configuration. All other calculated species have a singlet electronic ground state, except for NO, where the doublet spin state is largely more stable than the quartet spin state $\left(>123 \mathrm{kcal}_{\mathrm{mol}}{ }^{-1}\right)$.

The here applied method correctly reproduces the dimer dissociation energy (probably as a result of a fortunate cancellation of errors). Yet, the bond distances are slightly less well reproduced. Since we are mostly interested in the 
energetics in this study, we consider this of smaller importance.

Figure 1 shows the energy reaction profile for the $\mathrm{SO}_{2}+2 \mathrm{NO}$ reaction to yield $\mathrm{SO}_{3}$ and $\mathrm{N}_{2} \mathrm{O}$ for the electronic energy corrected for the zero-point energies (ZPE), the enthalpy changes at $298 \mathrm{~K}$ and the Gibbs energy at $298 \mathrm{~K}$ and 0.1 MPa. Starting with the reactants, $2 \mathrm{NO}$ and $\mathrm{SO}_{2}$ (M0), first the cis NO dimer is formed with the $\mathrm{SO}_{2}$ molecule at infinite distance (M1). Then the system goes through a transition state, where one NO molecule is nearly 90 degrees rotated and the $\widehat{\mathrm{ONNO}}$ dihedral angle changes from 0.0 in $\mathrm{M} 1$ to -84.3 degrees in T1. Next, the NO molecule continues its rotation to obtain a geometry where the two NO molecules are again in the same plane (M2). However, this configuration now more corresponds to the trans dimer, where one of the two molecules is shifted. Next, the transition takes place in which an oxygen atom is transferred from one $\mathrm{NO}$ molecule to the $\mathrm{SO}_{2}$ molecule. This transition state (T2) is characterized by an imaginary frequency of $i 745.1 \mathrm{~cm}^{-1}$ and a NO distance of $1.433 \AA$ in $\mathbf{T 1}(1.147 \AA$ in $\mathbf{M 2})$.

The very small energy barrier for the $\mathbf{M} 1 \rightleftharpoons \mathbf{T} \mathbf{1} \rightleftharpoons \mathbf{M} 2$ transition indicates a rapid cis/trans isomerization, while the significantly larger energy barrier for the $\mathbf{M} 2 \rightleftharpoons \mathbf{T} 2 \rightleftharpoons \mathbf{M} 3$ transition corresponds to the rate determining step of the overall reaction.

Upon considering the three energy profiles in Figure 1 it is seen that all three clearly show that the overall reaction is thermodynamically favored. The thermal corrections $(\mathrm{T}=0 \mathrm{~K}$ to $\mathrm{T}=298 \mathrm{~K}$ ) only have a minor impact on the relative stabilities of the different species, whereas the entropy significantly destabilizes both the transition state T2 and the final products M3. As can be seen from Figure 2, the entropy (or more precisely the $\mathrm{T} \Delta \mathrm{S}$ term) becomes smaller during the course of the reaction with an overall minimum for $\mathbf{T} 2$, where the three reactants essentially form one single species. An increase of the temperature, e.g. from 273 to $345 \mathrm{~K}$, has an endergonic contribution to the Gibbs energy, while a pressure increase from 0.1 to $5.0 \mathrm{MPa}$ yields an exergonic contribution to $\Delta \mathrm{G}$.

From Table 6 it is seen that the reaction barrier $\left(\Delta \mathrm{G}_{a}\right)$ that corresponds to 
Table 5: Properties of the cis NO dimer calculated at the M06 level, using the multi-reference CASSCF method [1], and experimental data. BE, ZPE, and $\mathrm{E}_{\text {elec }}$ stands for bonding energy, zero-point energy, and electronic energy, respectively.

\begin{tabular}{|c|c|c|c|}
\hline & $\begin{array}{c}\text { M06/ } \\
6-311+G(d, p)\end{array}$ & $\begin{array}{c}\operatorname{CASSCF}(18,14) / \\
6-311 \mathrm{G}(2 \mathrm{~d})\end{array}$ & Exp. \\
\hline $\mathrm{BE}\left(\mathrm{kcal} . \mathrm{mol}^{-1}\right)$ & 3.27 & 4.31 & $2.18 \quad 72]$ \\
\hline $\mathrm{BE}+\Delta \mathrm{ZPE}\left(\mathrm{kcal} \cdot \mathrm{mol}^{-1}\right)$ & 1.86 & 1.43 & - \\
\hline$\Delta \mathrm{E}\left(\mathrm{kcal} . \mathrm{mol}^{-1}\right)^{*}$ & 0.99 & 5.56 & - \\
\hline $\mathrm{r}(\mathrm{NN})(\AA)$ & 1.972 & 2.327 & $2.263 \quad 73$ \\
\hline $\mathrm{r}(\mathrm{NO})(\AA)$ & 1.146 & 1.159 & 1.15273 \\
\hline
\end{tabular}

Table 6: Energy changes (kcal.mol ${ }^{-1}$ ) of the most important transitions under different temperature and pressure conditions.

\begin{tabular}{|c|c|c|c|c|c|}
\hline & $\begin{array}{c}\Delta \mathrm{E}+\Delta \mathrm{ZPE} \\
(0 \mathrm{~K})\end{array}$ & $\begin{array}{c}\Delta \mathrm{H} \\
(298 \mathrm{~K})\end{array}$ & $\begin{array}{c}\Delta \mathrm{G} \\
(298 \mathrm{~K} \\
0.1 \mathrm{MPa})\end{array}$ & $\begin{array}{c}\Delta \mathrm{G} \\
(298 \mathrm{~K} \\
5 \mathrm{MPa})\end{array}$ & $\begin{array}{c}\Delta \mathrm{G} \\
(345 \mathrm{~K}, \\
0.1 \mathrm{MPa})\end{array}$ \\
\hline $\mathrm{Mo} \rightleftharpoons \mathrm{M} 1$ & -1.9 & -2.6 & 5.9 & 3.6 & 7.2 \\
\hline $\mathrm{M} 1 \rightleftharpoons \mathrm{T} 1$ & 1.3 & 1.7 & -0.2 & -0.2 & -0.4 \\
\hline $\mathrm{M} 1 \rightleftharpoons \mathrm{M} 2$ & 1.2 & 1.2 & 1.1 & 1.1 & 1.1 \\
\hline $\mathbf{M} 2 \rightleftharpoons \mathbf{T} 2\left(\Delta_{a}\right)$ & 33.7 & 32.4 & 46.9 & 44.6 & 49.2 \\
\hline $\mathbf{M 0} \rightleftharpoons \mathbf{M} 2\left(\Delta_{R}\right)$ & -39.8 & -41.3 & -29.0 & -31.4 & -27.1 \\
\hline
\end{tabular}

the rate determining step $(\mathbf{M} 2 \rightleftharpoons \mathbf{T} \mathbf{2})$, stays well beyond $+40 \mathrm{kcal}^{\mathrm{m}} \mathrm{mol}^{-1}$ in the investigated temperature and pressure ranges. It can thus be concluded that, in spite of the fact the reaction is thermodynamically favored $\left(\Delta \mathrm{G}_{R}\right)$, the overall reaction is kinetically prohibited. No chemical reaction will thus be considered hereafter in the study of $\mathrm{NO}+\mathrm{SO}_{2}$ systems.

\section{2. $\mathrm{VL}$ equilibrium for $\mathrm{NO}+\mathrm{SO}_{2}$ systems}

In this section, we propose new experimental VL data (generated using the apparatus described in section 2.1) for pressures up to $10 \mathrm{MPa}$. Molecular simulation tools were then used to supplement VL data at higher pressures. 
Finally, all VL data were used to optimize settings of the PPR78 EoS.

The apparatus described above has been used to acquire experimental data for $\mathrm{NO}+\mathrm{SO}_{2}$ binary mixtures. In this work, only vapour phases have been sampled. Experimental vapour phase compositions have been measured for the $\mathrm{NO}+\mathrm{SO}_{2}$ binary mixtures at $273.07 \mathrm{~K}, 313.21 \mathrm{~K}$, and $343.28 \mathrm{~K}$, and pressures up to $10 \mathrm{MPa}$. So-obtained mole fractions are reported in Table 7 Figure 3 plots pressures against experimental NO mole fractions for vapour phases of the studied systems. New experimental data are compared with those reported by $\mathrm{Xu}$ et al. [16], and both sets are consistent.

VL equilibrium data were obtained using MC molecular simulations performed in the Gibbs $N p T$ ensemble. The studied systems contained in between 1000 and 2000 molecules depending on the vicinity of the critical point of the studied mixture. For each MC simulation, the number of generated configurations ranged within $2.10^{8}$ and $6.10^{8}$ including the equilibration of the system and the production run. Statistical uncertainties associated to calculated phase properties were determined using the block averaging technique [74], and on liquid densities they are typically 1-2\%, but higher values are found at nearcritical temperatures as a result of larger fluctuations. Table 8 summarizes the calculated VL equilibrium data. Figure 3 presents pressure plotted against liquid and vapour phases mole fractions of NO, at 273.15, 293.15, 313.15, 324.15, and $345.15 \mathrm{~K}$. The considered temperatures are below the $\mathrm{SO}_{2}$ critical temperature $(430.75 \mathrm{~K})$, all phase diagrams exhibit a critical point, except that obtained at $273.15 \mathrm{~K}$ for which molecular simulations do not indicate an obvious closing trend of the phase envelope. Simulated critical coordinates of NO $+\mathrm{SO}_{2}$ mixtures were estimated by extrapolating MC simulation results with scaling laws, as described in equations (9) and (10), and detailed in previous works [6, 19, 20, 35]. The so-obtained critical coordinates, i.e. the critical density $\rho_{c}$, the critical composition $x_{c}$, and the critical pressure $P_{c}$, are given in 
Table 7: Experimental compositions of the vapour phase for $\mathrm{NO}+\mathrm{SO}_{2}$ binary mixtures at $273.07 \mathrm{~K}, 313.21 \mathrm{~K}$, and $343.28 \mathrm{~K} . n$ is the number of samples, $y_{N O}$ is the NO molar fraction in the vapour phase, and $\sigma_{y_{N O}}$ is the repeatability on vapour compositions. Umax(y) is 0.004 , $\mathrm{U}(\mathrm{P})$ is $6.10^{-4} \mathrm{MPa}$, and $\mathrm{U}(\mathrm{T})$ is $0.02 \mathrm{~K}$

\begin{tabular}{|c|c|c|c|}
\hline $\begin{array}{c}\mathrm{P} \\
(\mathrm{MPa})\end{array}$ & $n$ & $y_{N O}$ & $\sigma_{y_{N O}}$ \\
\hline \multicolumn{4}{|c|}{$T=273.07 \mathrm{~K}$} \\
\hline 0.4866 & 6 & 0.6580 & 0.0020 \\
\hline 1.0115 & 16 & 0.8283 & 0.0005 \\
\hline 2.0609 & 11 & 0.9096 & 0.0002 \\
\hline 3.2926 & 8 & 0.9372 & 0.0001 \\
\hline 6.1645 & 6 & 0.9551 & 0.0002 \\
\hline 10.8416 & 5 & 0.9618 & 0.0001 \\
\hline \multicolumn{4}{|c|}{$T=313.21 \mathrm{~K}$} \\
\hline 1.2488 & 9 & 0.4390 & 0.0030 \\
\hline 1.8063 & 8 & 0.6090 & 0.0020 \\
\hline 3.2242 & 6 & 0.7570 & 0.0050 \\
\hline 5.1040 & 5 & 0.8270 & 0.0040 \\
\hline 9.2503 & 10 & 0.8580 & 0.0020 \\
\hline 14.173 & 6 & 0.8810 & 0.0010 \\
\hline \multicolumn{4}{|c|}{$T=343.28 \mathrm{~K}$} \\
\hline 2.2584 & 5 & 0.3091 & 0.0060 \\
\hline 3.5153 & 6 & 0.5190 & 0.0040 \\
\hline 5.5226 & 7 & 0.6530 & 0.0060 \\
\hline 7.7624 & 7 & 0.7190 & 0.0040 \\
\hline 9.9743 & 6 & 0.7420 & 0.0090 \\
\hline 12.7731 & 6 & 0.7530 & 0.0040 \\
\hline 16.1085 & 4 & 0.7620 & 0.0030 \\
\hline
\end{tabular}


Table 8

$$
\begin{gathered}
\rho_{i}=\rho_{c}+\zeta \frac{\gamma}{2}\left(P_{c}-P\right)^{\beta}+\lambda\left(P_{c}-P\right), \\
x_{i}=x_{c}+\left(\lambda_{1}-\zeta \frac{\lambda_{2}}{2}\right)\left(P_{c}-P\right)-\zeta \frac{\mu}{2}\left(P_{c}-P\right)^{\beta},
\end{gathered}
$$

424

where, $\beta=0.325$, and $\zeta=1$ or -1 whether it refers to the liquid or vapour phase, respectively. Parameters $\left(\gamma, \lambda, \lambda_{1}, \lambda_{2}\right.$, and $\mu$ ) of equations (9) and (10) are regressed from a set of simulated coexistence data (i.e., $\left(P, \rho_{l}, \rho_{v}\right)$ and $\left(P, \mathrm{x}_{l}^{N O}, \mathrm{x}_{v}^{N O}\right)$, where subscripts $l$ and $v$ denote the liquid phase and the vapour phase, respectively). Figure 4 presents pressure plotted against liquid and vapour phase densities at 273.15, 293.15, 313.15, 324.15, and $345.15 \mathrm{~K}$. To the best of our knowledge, there is no volumetric data available in the literature to compare our results with.

Correlation of the $\mathrm{NO}+\mathrm{SO}_{2}$ binary system by means of the PPR78 EoS 16. was performed by $\mathrm{Xu}$ et al. who proposed to use $A_{12}=172.3 \mathrm{MPa}$ and $B_{12}=1343.2 \mathrm{MPa}$, see equation (4). Such parameters were however determined considering only six experimental data points. In this study, it was decided to refit such parameters over all the available VL equilibrium data. The following objective function (O.F.) was minimized:

$$
\text { O.F. }=\sum_{i=1}^{n . b .}\left|x_{i}^{e x p}-x_{i}^{c a l c}\left(T_{i}^{e x p}, P_{i}^{e x p}\right)\right|+\sum_{i=1}^{n . d .}\left|y_{i}^{e x p}-y_{i}^{c a l c}\left(T_{i}^{e x p}, P_{i}^{e x p}\right)\right|
$$

where, n.b. and n.d. designate the number of bubble and dew points, respectively. The derived optimal parameters for equation (4) - not so different from the ones obtained by Xu et al. [16] - , are $A_{12}=127.6 \mathrm{MPa}$ and $B_{12}=856.8$ MPa. Figures 3 shows data points and results of calculation obtained with the PPR78 EoS model. Isothermal phase diagrams at $\mathrm{T}=273.15 \mathrm{~K}, \mathrm{~T}=293.15$ $\mathrm{K}, \mathrm{T}=313.15 \mathrm{~K}, \mathrm{~T}=324.15 \mathrm{~K}, \mathrm{~T}=345.15 \mathrm{~K}$ (Figure 3) and the global phase equilibrium diagram for the $\mathrm{NO}+\mathrm{SO}_{2}$ mixture (Figure 5) were calculated. 
Table 8: Calculated vapour liquid equilibrium compositions and densities for the $\mathrm{NO}+\mathrm{SO}_{2}$ mixture at different temperatures.

\begin{tabular}{|c|c|c|c|c|c|c|c|c|c|c|c|}
\hline $\begin{array}{c}T \\
(\mathrm{~K})\end{array}$ & $\begin{array}{c}P \\
(\mathrm{MPa})\end{array}$ & $\mathrm{x}_{v}^{N O}$ & $\begin{array}{c}\rho_{v} \\
\left(\mathrm{~kg} \cdot \mathrm{m}^{-3}\right.\end{array}$ & $\mathrm{x}_{l}^{N O}$ & $\begin{array}{c}\rho_{l} \\
\left(\mathrm{~kg} \cdot \mathrm{m}^{-3}\right.\end{array}$ & $\begin{array}{c}T \\
(\mathrm{~K})\end{array}$ & $\begin{array}{c}P \\
(\mathrm{MPa})\end{array}$ & $\mathrm{x}_{v}^{N O}$ & $\begin{array}{c}\rho_{v} \\
\left(\mathrm{~kg} \cdot \mathrm{m}^{-3}\right.\end{array}$ & $\mathrm{x}_{l}^{N O}$ & $\begin{array}{c}\rho_{l} \\
\left(\mathrm{~kg} \cdot \mathrm{m}^{-3}\right)\end{array}$ \\
\hline \multirow[t]{16}{*}{273.15} & $0.2^{\#}$ & 0.00000 & 4.6 & 0.00000 & 1440.1 & 313.15 & $0.7^{\#}$ & 0.00000 & 18.7 & 0.00000 & 1332.6 \\
\hline & 1.5 & 0.01142 & 23.4 & 0.87258 & 1435.3 & & 1.5 & 0.00808 & 28.6 & 0.52200 & 1325.5 \\
\hline & 3.0 & 0.02517 & 44.9 & 0.93108 & 1425.8 & & 3.0 & 0.02238 & 48.2 & 0.73322 & 1318.2 \\
\hline & 5.0 & 0.04194 & 75.2 & 0.95070 & 1417.4 & & 5.0 & 0.04151 & 75.1 & 0.82048 & 1307.1 \\
\hline & 10.0 & 0.07994 & 158.2 & 0.96230 & 1399.4 & & 10.0 & 0.08840 & 147.2 & 0.87900 & 1281.2 \\
\hline & 15.0 & 0.11936 & 248.3 & 0.96373 & 1378.1 & & 15.0 & 0.13611 & 224.9 & 0.88985 & 1252.3 \\
\hline & 20.0 & 0.14771 & 342.8 & 0.95719 & 1366.1 & & 20.0 & 0.18079 & 307.9 & 0.88492 & 1226.7 \\
\hline & 25.0 & 0.17037 & 430.5 & 0.94785 & 1358.5 & & 25.0 & 0.22725 & 391.8 & 0.87307 & 1198.5 \\
\hline & 30.0 & 0.19672 & 502.8 & 0.93996 & 1346.1 & & 30.0 & 0.27163 & 477.7 & 0.85127 & 1171.6 \\
\hline & 35.0 & 0.22173 & 561.0 & 0.93484 & 1334.9 & & 35.0 & 0.30865 & 569.8 & 0.81457 & 1152.1 \\
\hline & 40.0 & 0.23590 & 615.2 & 0.92370 & 1332.8 & & 40.0 & 0.38648 & 665.2 & 0.76935 & 1089.9 \\
\hline & 45.0 & 0.26086 & 657.5 & 0.91681 & 1321.4 & & $42.7^{*}$ & 0.56971 & 907.9 & 0.56971 & 907.9 \\
\hline & 50.0 & 0.28289 & 691.2 & 0.91214 & 1312.0 & 324.15 & $0.9^{\#}$ & 0.00000 & 24.6 & 0.00000 & 1297.1 \\
\hline & 55.0 & 0.30074 & 725.5 & 0.90456 & 1306.8 & & 3.2 & 0.02213 & 54.4 & 0.65618 & 1286.2 \\
\hline & 60.0 & 0.31492 & 751.9 & 0.90049 & 1304.0 & & 5.0 & 0.03982 & 78.1 & 0.75245 & 1275.8 \\
\hline & 65.0 & 0.32828 & 784.4 & 0.88859 & 1302.1 & & 10.0 & 0.08817 & 149.6 & 0.83536 & 1247.6 \\
\hline \multirow[t]{16}{*}{293.15} & $0.3^{\#}$ & 0.00000 & 9.5 & 0.00000 & 1384.9 & & 15.0 & 0.13662 & 225.5 & 0.85384 & 1218.9 \\
\hline & 1.5 & 0.01046 & 25.0 & 0.73761 & 1381.8 & & 20.0 & 0.19058 & 306.6 & 0.85384 & 1183.0 \\
\hline & 3.0 & 0.02371 & 45.3 & 0.85498 & 1375.5 & & 25.0 & 0.24291 & 398.8 & 0.83357 & 1147.6 \\
\hline & 5.0 & 0.04170 & 73.6 & 0.90118 & 1366.4 & & 30.0 & 0.30027 & 490.6 & 0.80785 & 1108.1 \\
\hline & 10.0 & 0.08582 & 149.5 & 0.93121 & 1340.9 & & 35.0 & 0.37495 & 595.1 & 0.76037 & 1047.0 \\
\hline & 15.0 & 0.12644 & 232.1 & 0.93359 & 1319.7 & & $37.8^{*}$ & 0.57676 & 836.2 & 0.57676 & 836.2 \\
\hline & 20.0 & 0.16297 & 318.6 & 0.92786 & 1300.8 & 345.15 & $1.6^{\#}$ & 0.00000 & 42.1 & 0.00000 & 1232.3 \\
\hline & 25.0 & 0.20117 & 401.6 & 0.91891 & 1279.2 & & 3.9 & 0.02411 & 73.9 & 0.50703 & 1223.6 \\
\hline & 30.0 & 0.24074 & 478.7 & 0.90658 & 1256.3 & & 7.0 & 0.05746 & 113.9 & 0.68165 & 1197.1 \\
\hline & 35.0 & 0.27427 & 544.2 & 0.89477 & 1238.9 & & 10.0 & 0.09115 & 156.6 & 0.74079 & 1173.3 \\
\hline & 40.0 & 0.30313 & 602.5 & 0.88039 & 1225.0 & & 15.0 & 0.15237 & 231.7 & 0.77920 & 1128.3 \\
\hline & 45.0 & 0.33635 & 660.4 & 0.86152 & 1208.3 & & 20.0 & 0.21368 & 318.0 & 0.77616 & 1086.2 \\
\hline & 50.0 & 0.36514 & 716.1 & 0.83725 & 1194.2 & & 25.0 & 0.28384 & 420.9 & 0.74666 & 1033.5 \\
\hline & 55.0 & 0.41668 & 819.3 & 0.76114 & 1159.0 & & 27.0 & 0.31836 & 456.2 & 0.73929 & 1001.0 \\
\hline & $57.7^{*}$ & 0.58231 & 1007.4 & 0.58231 & 1007.4 & & 29.0 & 0.36071 & 508.8 & 0.71747 & 960.8 \\
\hline & & & & & & & $31.3^{*}$ & 0.54987 & 744.1 & 0.54987 & 744.1 \\
\hline
\end{tabular}

* Critical coordinates obtained using extended scaling laws, see equations (9) and (10).

\# Pure $\mathrm{SO}_{2}$ liquid vapour equilibrium data2obtained using GIBBS NVT MC simulations. 
As shown by Figure [5, the $\mathrm{NO}+\mathrm{SO}_{2}$ mixture exhibits a type III phase behaviour according to the classification scheme by van Konynenburg and Scott [75, 76]. The VL equilibrium data of such systems are acknowledged to be difficult to correlate with an EoS, and it is thus not surprising to observe deviations between calculated and experimental data points. In particular, the use of a one-parameter $a^{E}$ model, like the van Laar model, in the advanced mixing rules implemented in this study tends to strongly overestimate critical pressures predicted using MC simulations. From our experience [24, 25, 26], the quality of the correlation can however be significantly improved by coupling the PR EoS with the residual part of the Wilson $a^{E}$ model. For a binary system, such a model writes as follows:

$$
\begin{aligned}
\frac{a_{r e s}^{\gamma W i l s o n}(T, \zeta)}{R T}= & -z_{1} \ln \left[\Phi_{1}+\Phi_{2} \exp \left(-\frac{A_{12}}{R T}\right)\right] \\
& -z_{2} \ln \left[\Phi_{1} \exp \left(-\frac{A_{21}}{R T}\right)+\Phi_{2}\right]
\end{aligned}
$$

$A_{12}$ and $A_{21}$ are the two adjustable parameters and $\Phi_{i}=z_{i} \mathbf{v}_{i} / \sum_{j=1}^{N C}\left(z_{j} \mathbf{v}_{j}\right)$ is the volume fraction of molecule $i$. Such an activity coefficient model was used in conjunction with equation (1) after setting parameter $s$ to 2 and parameter $\Lambda$ to -0.52398 (this is the value proposed by Michelsen during the derivation of the modified Huron-Vidal mixing rule [77]). As was done previously with the PPR78 EoS model, the objective function defined by equation (11) was minimized. The optimal parameters, determined for each isothermal group of data, are reported in Table 9. Both $A_{N O-\mathrm{SO}_{2}}$ and $A_{\mathrm{SO}_{2}-\mathrm{NO}}$ vary according to the temperature, and the application of a curve fitting leads to polynomial functions of degree two allowing temperature interpolations.

Figure 3 shows data points and results of calculations obtained after coupling

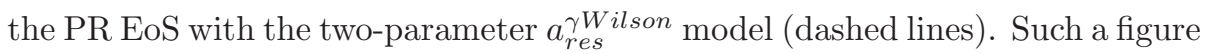
clearly demonstrates that the correlation of both the critical regions and the dew curves have been highly improved as compared to PR with one-parameter $a^{E}$ model (solid lines). 
Table 9: Parameters $A_{12}$ and $A_{21}$ of the Wilson $a^{E}$ model to use with the advanced mixing rules employed in this study.

\begin{tabular}{cccccc}
\hline$T(\mathrm{~K})$ & 273.15 & 293.15 & 313.15 & 324.15 & 345.15 \\
\hline$A_{\mathrm{NO}-\mathrm{SO}_{2}}$ & 180 & 238 & 423 & 603 & 830 \\
$A_{\mathrm{SO}_{2}-\mathrm{NO}}$ & 180 & -57 & -299 & -420 & -533 \\
\hline
\end{tabular}

\subsection{Henry constants of gases in water}

The Henry constant $\left(K_{H}\right)$ provides information about interactions between the solute and the solvent. At $\mathrm{T}$ and $\mathrm{P}$ conditions, the Henry constant for a solute $i$ (i.e. gas, in this work) in a solvent (i.e. water or brines, in this work) is defined as follows:

$$
K_{H}(\mathrm{~T}, \mathrm{P})=\lim _{x_{i} \rightarrow 0} \frac{f_{i}}{x_{i}},
$$

where $f_{i}$ and $x_{i}$ are the fugacity and the mole fraction of the solute $i$, respectively. $f_{i}$ is related to the excess chemical potential $\left(\bar{\mu}_{i}\left(\mathrm{~T}, \mathrm{P}, x_{i}\right)\right)$ by:

$$
\frac{f_{i}}{x_{i}}=\mathrm{P} \exp \left(\beta \bar{\mu}_{i}\left(\mathrm{~T}, \mathrm{P}, x_{i}\right)\right)
$$

where $\beta=1 / k_{\mathrm{b}} T$ and $k_{\mathrm{b}}$ is the Boltzmann's constant. Solubilities of gases in a solvent have been computed using the Widom test insertion technique which consists in randomly inserting a particle in the solvent. The difference in potential energy $\left(\Delta U^{+}\right)$resulting from the particle insertion in the solvent is calculated, and the excess chemical potential at infinite dilution is evaluated using equation (15).

$$
\bar{\mu}_{i}\left(\mathrm{~T}, \mathrm{P}, x_{i}\right)=-\frac{1}{\beta} \ln \left\langle\frac{\beta P V}{N+1} \exp \left(-\beta \Delta U^{+}\right)\right\rangle_{N p T},
$$

with $V$ the volume of the system, see reference [78] for more details.

We performed MC simulations in the $N p T$ ensemble for $\mathrm{SO}_{2} / \mathrm{H}_{2} \mathrm{O}, \mathrm{NO} / \mathrm{H}_{2} \mathrm{O}$ systems, and for three other systems: $\mathrm{CO}_{2} / \mathrm{H}_{2} \mathrm{O}, \mathrm{O}_{2} / \mathrm{H}_{2} \mathrm{O}$, and $\mathrm{N}_{2} / \mathrm{H}_{2} \mathrm{O}$, in order to obtain Henry constant values. Temperatures ranged from $273.15 \mathrm{~K}$ to 
$623.15 \mathrm{~K}$, and the pressure was set to the corresponding vapour pressure, $P^{s a t}$, of water. Simulation boxes contained $10^{3}$ water molecules represented with the TIP4P/2005 potential, as this latter is known to better reproduce liquid densities as compared to the SPC/E potential [52, 53]. Note that no finite size effect has been detected by Orozco et al. using simulation boxes with 300 water molecules [79]. Gas molecules were described using force fields listed in Table2 For each system, $5 \times 10^{8} \mathrm{MC}$ configurations were generated and $K_{H}$ evaluated using equations (14) and (15). The statistical uncertainty associated to simulated $K_{H}$ value is $20 \%$, determined using the block averaging technique [74]. Lísal et al. have generated $K_{H}$ values for $\mathrm{CO}_{2}$ using $\mathrm{MC}$ simulations together with SPC based water potentials and three potentials including the EPM2 to mimic $\mathrm{CO}_{2}$ behavior, and authors showed that the combination SPC/E - EPM2 qualitatively predicts the temperature dependence of the Henry constant [78]. This latter combination fails in reproducing the maximum in $K_{H}$ experimentally observed at $c a .420 \mathrm{~K}$ which corresponds to the temperature at which the enthalpy of solution is zero [78, 80]. More recently, Orozco et al. showed that $K_{H}$ values obtained with TIP4P/2005 - EPM2 are lower than predictions using SPC/E - EPM2 79]. Simultaion results reported in Table 10 supplement these latter data with $K_{H}$ values for temperatures up to $623.15 \mathrm{~K}$, using the TIP4P/2005 - EPM2 model. The simulated maximum in $K_{H}$ is observed at ca. $450 \mathrm{~K}$, but simulation results overestimate experimental $K_{H}$ values. Molecular simulations were also performed to obtain $K_{H}$ values for $\mathrm{SO}_{2}, \mathrm{NO}, \mathrm{O}_{2}$, and $\mathrm{N}_{2}$ in water for temperatures ranging from $273.15 \mathrm{~K}$ to $623.15 \mathrm{~K}$, see Table 10. Figure 6 illustrates $K_{H}$ evolutions as a function of the temperature, for gases of interest. Beside NO, molecular simulation results reasonably agree with correlations of experimental values [81, 82], and the temperature value at which the enthalpy of solution is zero - the maximum in $K_{H}$ - is well estimated.

\subsection{Solubility of sulphur dioxide in pure water}

In the case of sulphur dioxide (gas with the lowest $K_{H}$ values in Table 10), we propose to supplement the information (Henry constant values) provided in 
Table 10: Simulated Henry constants for $\mathrm{SO}_{2}, \mathrm{CO}_{2}, \mathrm{NO}, \mathrm{O}_{2}$, and $\mathrm{N}_{2}$ in water for temperatures ranging from $273.15 \mathrm{~K}$ to $623.15 \mathrm{~K}$.

\begin{tabular}{cccccc} 
& \multicolumn{5}{c}{ Henry constant (MPa.mol/mol) } \\
Temperature $(\mathrm{K})$ & $\mathrm{SO}_{2}$ & $\mathrm{CO}_{2}$ & $\mathrm{NO}$ & $\mathrm{O}_{2}$ & $\mathrm{~N}_{2}$ \\
\hline 273.15 & 3 & 174 & 1826 & 2308 & 6172 \\
323.15 & 36 & 510 & 4838 & 6333 & 15683 \\
373.15 & 70 & 885 & 6150 & 6871 & 14354 \\
423.15 & 104 & 934 & 5061 & 5252 & 9522 \\
473.15 & 134 & 976 & 3447 & 3806 & 6167 \\
523.15 & 150 & 808 & 2185 & 2354 & 3405 \\
573.15 & 138 & 564 & 1252 & 1390 & 1836 \\
623.15 & 120 & 360 & 671 & 708 & 854 \\
\hline
\end{tabular}

Table 10 by computing $\mathrm{SO}_{2}$ solubility in water at higher pressure values beyond the Henry regime. At the two investigated temperatures (298.15 K and 323.15 $\mathrm{K}$ ), phase diagrams for the $\mathrm{SO}_{2}+\mathrm{H}_{2} \mathrm{O}$ binary mixtures exhibit a liquid vapour $(\mathrm{L} 1, \mathrm{~V})$ equilibrium domain at the lowest pressures, a liquid-liquid (L1,L2) equilibrium domain at the highest pressures, with a three-phase line $(\mathrm{L} 1, \mathrm{~L} 2, \mathrm{~V})$ in between these two domains, and a tiny liquid vapour $(\mathrm{L} 2, \mathrm{~V})$ domain just above the three-phase line near the pure $\mathrm{SO}_{2}$ axis. $\mathrm{MC}$ molecular simulations were performed in the Gibbs ensemble for pressures up to $10 \mathrm{MPa}$, in the Gibbs- $N p T$ ensemble for diphasic systems and in the Gibbs-NVT ensemble for triphasic systems. The studied systems contained in between 550 and 1000 molecules. For each MC simulation, the number of generated configurations ranged within $2.10^{8}$ and $4.10^{8}$ including the equilibration of the system and the production run. Table 11 presents simulated phase compositions for the $\mathrm{SO}_{2}+\mathrm{H}_{2} \mathrm{O}$ systems, and Figure 7 proposes comparisons with available experimental data, for the $\mathrm{H}_{2} \mathrm{O}$-rich part of the pressure-composition diagram. Table 11 contains information regarding coordinates of the three-phase line in between the vapour-liquid and the liquid-liquid equilibrium domains, located at 0.41 $\mathrm{MPa}$ and $0.86 \mathrm{MPa}$ at $298.15 \mathrm{~K}$ and $323.15 \mathrm{~K}$, respectively. Comparisons with available experimen- 
tal data performed in Figure 7 indicate that the $\mathrm{SO}_{2}$ content of the water-rich branch of the liquid-liquid domain is slightly underestimated by molecular simulations. Using solubility data presented in Table 11, one can estimate Henry constant values: $9 \mathrm{MPa} . \mathrm{mol} / \mathrm{mol}$ at $298.15 \mathrm{~K}$ and $33 \mathrm{MPa} . \mathrm{mol} / \mathrm{mol}$ at 323.15 $\mathrm{K}$, in line with values reported in Table 10.

\subsection{Liquid densities and osmotic pressures for brines}

For binary $\mathrm{H}_{2} \mathrm{O} / \mathrm{NaCl}$ and $\mathrm{H}_{2} \mathrm{O} / \mathrm{CaCl}_{2}$ systems, we propose to supplement the information available in the litterature regarding the prediction of brine liquid density values using non-polarizable intermolecular potentials. Thus, we performed HMCMD simulations in the $N p T$ ensemble for $\mathrm{NaCl}$ or $\mathrm{CaCl}_{2}$ aqueous solutions with molalities from 0 to $5 \mathrm{~mol} \cdot \mathrm{kg}^{-1}$, at $298 \mathrm{~K}$ and $0.1 \mathrm{MPa}$. Our simulation boxes contain 500 water molecules and up to 45 salt molecules $(\mathrm{NaCl}$ or $\mathrm{CaCl}_{2}$ ). We did not investigate size effects but Tsai et al., who considered similar binary systems with smaller simulation box size, have reported no or negligible finite-size effects [63].

Table 12 details obtained simulated density values for $\mathrm{NaCl}$ aqueous solutions at $298 \mathrm{~K}$ and $0.1 \mathrm{MPa}$. Figure 8 presents the simulated density values as a function of brine molal concentrations for each of the considered couple water - NaCl models. Predictions obtained with all combinations follow the experimental trend, i.e. the binary system density increases with the salt molality. Among the tested combinaisons, TIP4P/2005 - OPLS leads to the most accurate predictions with respect to experimental data proposed by Zhang and Han [83], with a MAE of $2.5 \mathrm{~kg} \cdot \mathrm{m}^{-3}$. The use of the SPC/E - OPLS combinaison leads to a similar predictive accuracy with a MAE of $2.6 \mathrm{~kg} \cdot \mathrm{m}^{-3}$. Although the Wheeler potential has been designed using the SPC/E model, its combination with the TIP4P/2005 water model results in satisfactory predictions with a MAE of $4.0 \mathrm{~kg} \cdot \mathrm{m}^{-3}$. The use of other tested combinations significantly underestimates density values for all investigated salt molalities. The osmotic pressure is an interesting thermodynamic property to evaluate the accuracy of force fields for concentrated aqueous salt solutions. MD simulations were per- 
Table 11: Phase compositions for the $\mathrm{SO}_{2}+\mathrm{H}_{2} \mathrm{O}$ binary systems at $298.15 \mathrm{~K}$ and 323.15 $\mathrm{K}$, obtained using MC molecular simulation. $\mathrm{V}$ denotes the vapour phase, and L1 and L2 stand for $\mathrm{H}_{2} \mathrm{O}$-rich and $\mathrm{SO}_{2}$-rich liquids, respectively. Water molecules are mimicked using the TIP4P/2005 potential.

\begin{tabular}{cccc}
\hline $\mathrm{P}$ & \multicolumn{3}{c}{ Molar fraction of $\mathrm{SO}_{2}$} \\
$(\mathrm{MPa})$ & $\mathrm{L} 1$ & $\mathrm{~L} 2$ & $\mathrm{~V}$ \\
\hline \multicolumn{4}{c}{$\mathrm{T}=298.15 \mathrm{~K}$} \\
0.05 & 0.00429 & - & 0.98663 \\
0.10 & 0.01071 & - & 0.99304 \\
0.41 & 0.04427 & 0.99020 & 0.99833 \\
0.42 & - & 1.00000 & 1.00000 \\
0.50 & 0.04040 & 0.98755 & - \\
1.00 & 0.04124 & 0.98879 & - \\
3.00 & 0.04143 & 0.98819 & - \\
5.00 & 0.04254 & 0.99163 & - \\
10.00 & 0.04229 & 0.97244 & - \\
& $\mathrm{T}=323.15 \mathrm{~K}$ & \\
0.05 & 0.00165 & - & 0.93193 \\
0.10 & 0.00397 & - & 0.96244 \\
0.50 & 0.01547 & - & 0.99275 \\
0.86 & 0.04312 & 0.98178 & 0.99588 \\
0.91 & - & 1.00000 & 1.00000 \\
1.00 & 0.03925 & 0.98104 & - \\
3.00 & 0.04412 & 0.97657 & - \\
5.00 & 0.03935 & 0.97821 & - \\
10.00 & 0.03444 & 0.97999 & - \\
\hline
\end{tabular}


formed for the TIP4P/2005 - OPLS and the SPC/E - OPLS combinations, considering four salt molal concentrations (m from 1.0 to $4.5 \mathrm{~mol} . \mathrm{kg}^{-1}$ ), at 298 K. Table 14 presents simulation results, and Figure 9(A) proposes a comparison of predicted values with experimental data extracted from reference [84]. The comparison shows that osmotic pressure values obtained with the TIP4P/2005 - OPLS combination are in better agreement with respect to reference experimental data $(\mathrm{MAE}=0.4 \mathrm{MPa})$ as compared to osmotic pressures calculated with the SPC/E - OPLS combination $(\mathrm{MAE}=1.5 \mathrm{MPa})$. Consequently, the TIP4P/2005 - OPLS will be the only combination considered hereafter for binary $\mathrm{H}_{2} \mathrm{O} / \mathrm{NaCl}$ systems.

Table 13 summarizes density values for aqueous $\mathrm{CaCl}_{2}$ solutions, using HMCMD simulations at $298 \mathrm{~K}$ and $0.1 \mathrm{MPa}$. Figure 8 presents the simulated density values as a function of brine molal concentrations for each of the considered couple water $-\mathrm{CaCl}_{2}$ models. Results show that the best density predictions are obtained using the potential developed by Goo et al. and the TIP4P/2005 water models, with a MAE of $7.6 \mathrm{~kg} \cdot \mathrm{m}^{-3}$. Tsai et al. recently studied $\mathrm{CaCl}_{2}$ aqueous solutions by means of molecular simulations and only SPC based water models, and concluded that the SPC/E - Aqv outperforms all other tested combinations. From comparisons performed in Figure 8 , we demonstrate that when using SPC/E water model, more accurate density predictions can be obtained with the potential developed by Goo et al., with a MAE of $9.6 \mathrm{~kg} . \mathrm{m}^{-3}$. Then, MD simulations were performed using the TIP4P/2005 - GoT and the SPC/E - GoS combinations, and simulation conditions similar to those performed in the case of $\mathrm{NaCl}$ aqueous solutions in order to investigate osmotic pressures. Table 14 presents simulation results, and Figure 9(B) proposes a comparison of predicted values with experimental data extracted from the work of Staples and Nuttall [85]. Comparisons show that none of the two investigated combinations successfully reproduces experimental osmotic pressure values, with MAE greater than $20 \mathrm{MPa}$. Hereafter, the TIP4P/2005 - GoT model will be used to mimic the behavior of $\mathrm{CaCl}_{2}$ aqueous solutions. 
Table 12: Simulated liquid density values for aqueous $\mathrm{NaCl}$ solutions varying the salt molal concentration from 0 to $5 \mathrm{~mol} . \mathrm{kg}^{-1}$, at $298 \mathrm{~K}$ and $0.1 \mathrm{MPa}$, obtained using HMCMD simulations in the $N p T$ ensemble and force fields listed in Table 3

\begin{tabular}{|c|c|c|c|c|c|}
\hline $\begin{array}{c}\text { Water }-\mathrm{NaCl} \\
\text { models }\end{array}$ & $\begin{array}{c}\mathrm{m} \\
\left(\mathrm{mol}^{\mathrm{kg}} \mathrm{kg}^{-1}\right)\end{array}$ & $\begin{array}{c}\text { Density } \\
\left(\mathrm{kg} \cdot \mathrm{m}^{-3}\right)\end{array}$ & $\begin{array}{c}\text { Water }-\mathrm{NaCl} \\
\text { models }\end{array}$ & $\begin{array}{c}\mathrm{m} \\
\left(\mathrm{mol} \cdot \mathrm{kg}^{-1}\right)\end{array}$ & $\begin{array}{c}\text { Density } \\
\left(\mathrm{kg} \cdot \mathrm{m}^{-3}\right)\end{array}$ \\
\hline TIP4P /2005 & 0 & 997.6 & TIP4P/2005 - Whee & 1 & 1038.2 \\
\hline \multirow[t]{5}{*}{ TIP4P/2005 - OPLS } & 1 & 1038.9 & & 2 & 1071.9 \\
\hline & 2 & 1074.8 & & 3 & 1102.3 \\
\hline & 3 & 1110.1 & & 4 & 1129.8 \\
\hline & 4 & 1140.3 & & 5 & 1157.2 \\
\hline & 5 & 1164.5 & $\mathrm{SPC} / \mathrm{E}$ & 0 & 999.0 \\
\hline \multirow[t]{5}{*}{ TIP4P/2005 - GoT } & 1 & 1036.4 & $\mathrm{SPC} / \mathrm{E}-\mathrm{OPLS}$ & 1 & 1035.6 \\
\hline & 2 & 1069.7 & & 2 & 1071.5 \\
\hline & 3 & 1098.4 & & 3 & 1106.6 \\
\hline & 4 & 1126.4 & & 4 & 1132.9 \\
\hline & 5 & 1148.0 & & 5 & 1159.1 \\
\hline \multirow[t]{5}{*}{ TIP4P/2005 - Aqv } & 1 & 1030.1 & $\mathrm{SPC} / \mathrm{E}-\mathrm{GoS}$ & 1 & 1032.7 \\
\hline & 2 & 1060.7 & & 2 & 1060.5 \\
\hline & 3 & 1082.1 & & 3 & 1088.6 \\
\hline & 4 & 1105.6 & & 4 & 1116.8 \\
\hline & 5 & 1123.9 & & 5 & 1136.2 \\
\hline
\end{tabular}


Table 13: Simulated liquid density values for aqueous $\mathrm{CaCl}_{2}$ solutions varying the salt molal concentration from 0 to $5 \mathrm{~mol} \cdot \mathrm{kg}^{-1}$, at $298 \mathrm{~K}$ and $0.1 \mathrm{MPa}$, obtained using HMCMD simulations in the $N p T$ ensemble and force fields listed in Table 4

\begin{tabular}{|c|c|c|c|c|c|}
\hline $\begin{array}{c}\text { Water }-\mathrm{CaCl}_{2} \\
\text { models }\end{array}$ & $\begin{array}{c}\mathrm{m} \\
\left(\mathrm{mol}^{\mathrm{kg}} \mathrm{kg}^{-1}\right)\end{array}$ & $\begin{array}{c}\text { Density } \\
\left(\mathrm{kg} \cdot \mathrm{m}^{-3}\right)\end{array}$ & $\begin{array}{c}\text { Water }-\mathrm{CaCl}_{2} \\
\text { models }\end{array}$ & $\begin{array}{c}\mathrm{m} \\
\left(\mathrm{mol} . \mathrm{kg}^{-1}\right)\end{array}$ & $\begin{array}{c}\text { Density } \\
\left(\mathrm{kg} \cdot \mathrm{m}^{-3}\right)\end{array}$ \\
\hline TIP4P /2005 & 0 & 997.6 & $\mathrm{SPC} / \mathrm{E}$ & 0 & 999.0 \\
\hline \multirow[t]{5}{*}{ TIP4P/2005 - Aqv } & 1 & 1078.0 & $\mathrm{SPC} / \mathrm{E}-\mathrm{GoS}$ & 1 & 1083.3 \\
\hline & 2 & 1143.7 & & 2 & 1152.6 \\
\hline & 3 & 1196.1 & & 3 & 1217.9 \\
\hline & 4 & 1232.4 & & 4 & 1273.4 \\
\hline & 5 & 1264.3 & & 5 & 1315.6 \\
\hline \multirow[t]{5}{*}{ TIP4P/2005 - Matt } & 1 & 1061.3 & $\mathrm{SPC} / \mathrm{E}-$ Pred & 1 & 1077.2 \\
\hline & 2 & 1108.1 & & 2 & 1135.2 \\
\hline & 3 & 1156.9 & & 3 & 1186.8 \\
\hline & 4 & 1194.2 & & 4 & 1218.4 \\
\hline & 5 & 1231.2 & & 5 & 1252.7 \\
\hline \multirow[t]{5}{*}{ TIP4P/2005 - GoT } & 1 & 1082.4 & $\mathrm{SPC} / \mathrm{E}-\mathrm{Aqv}$ & 1 & 1077.1 \\
\hline & 2 & 1152.6 & & 2 & 1137.9 \\
\hline & 3 & 1218.7 & & 3 & 1193.2 \\
\hline & 4 & 1273.5 & & 4 & 1225.7 \\
\hline & 5 & 1326.5 & & 5 & 1266.6 \\
\hline
\end{tabular}

Table 14: Osmotic pressure values ( $\mathrm{MPa}$ ) for aqueous $\mathrm{NaCl}$ and $\mathrm{CaCl}_{2}$ solutions varying the salt molal concentration from 1 to $5 \mathrm{~mol} . \mathrm{kg}^{-1}$, at $298 \mathrm{~K}$ and $0.1 \mathrm{MPa}$, obtained using MD simulations in the NVT ensemble and force fields listed in Tables 3 and 4 .

\begin{tabular}{|c|c|c|c|c|c|c|c|}
\hline \multicolumn{4}{|c|}{$\mathrm{NaCl}$} & \multicolumn{4}{|c|}{$\mathrm{CaCl}_{2}$} \\
\hline $\mathrm{m}$ & $\begin{array}{l}\text { TIP4P / } 2005 \\
- \text { OPLS }\end{array}$ & $\mathrm{m}$ & $\begin{array}{l}\text { SPC/E } \\
- \text { OPLS }\end{array}$ & $\mathrm{m}$ & $\begin{array}{l}\text { TIP } 4 \mathrm{P} / 2005 \\
-\mathrm{GoT}\end{array}$ & $\mathrm{m}$ & $\begin{array}{l}\mathrm{SPC} / \mathrm{E} \\
-\mathrm{GoS}\end{array}$ \\
\hline 1.04 & 4.22 & 1.03 & 4.82 & 1.0 & 4.82 & 1.0 & 6.98 \\
\hline 2.19 & 10.27 & 2.10 & 9.34 & 2.3 & 13.56 & 2.3 & 17.00 \\
\hline 3.51 & 18.73 & 3.33 & 19.04 & 3.6 & 22.67 & 3.6 & 30.59 \\
\hline 4.49 & 24.36 & 4.48 & 27.78 & 4.9 & 38.51 & 4.9 & 49.07 \\
\hline
\end{tabular}




\subsection{Henry constants of gases in brines}

We performed MC simulations in the $N p T$ ensemble to compute Henry constant values for $\mathrm{SO}_{2}, \mathrm{CO}_{2}, \mathrm{NO}, \mathrm{O}_{2}$, and $\mathrm{N}_{2}$ in brines. Investigated temperatures ranged from $298.15 \mathrm{~K}$ to $373.15 \mathrm{~K}$, and the pressure was set to the corresponding vapour pressure of the brine which is assumed similar to that of water in the range of investigated salt concentrations. From conclusions drawn in previous sections, simulation boxes contained $10^{3}$ water molecules represented with the TIP4P/2005 potential, and $\mathrm{NaCl}$ and $\mathrm{CaCl}_{2}$ mimicked using the OPLS (see Table 3) and GoT (see Table 4) parameterizations, respectively. Gas molecules were described using force fields listed in Table 2. Up to $2 \times 10^{9} \mathrm{MC}$ configurations were generated for each system, and $K_{H}$ evaluated according to equations (13) to (15). The mole fraction of the solute (gas molecule inserted in the simulation box $)$ is defined as $1 /(\mathrm{N}+1)$, with $\mathrm{N}$ the number of solvent species in the simulation box. In the case of brines, $\mathrm{N}$ can be estimated either considering anions and cations coupled or not; salt ions are supposed uncoupled hereafter. Due to the low acceptance of insertions for high salt concentrations and resulting problems of statistics, we chose to limit the present study to brines with salt molalities up to $3 \mathrm{~mol} \cdot \mathrm{kg}^{-1}$. Tables 15 and 16 report simulated Henry constant values for $\mathrm{NaCl}$ and $\mathrm{CaCl}_{2}$ aqueous solutions, respectively. Figure 10 illustrates $K_{H}$ values simulated for gases in $\mathrm{NaCl}$ aqueous solutions. The statistical uncertainty associated to simulated $K_{H}$ value is $20 \%$, determined using the block averaging technique [74]. Our proposed sets of simulated Henry constant values can be used to estimate Sechenov constant $\left(K_{S}\right)$ values as defined in equation (16) [86, 87].

$$
\log \left(\frac{K_{H}^{b}}{K_{H}^{w}}\right)=K_{S} \cdot m
$$

where $m$ is the salt molality, and $K_{H}^{w}$ and $K_{H}^{b}$ denotes Henry constants in water and brine, respectively. For studied temperatures and $\mathrm{NaCl}$ brines, $K_{S}$ values for $\mathrm{CO}_{2}, \mathrm{NO}, \mathrm{O}_{2}$, and $\mathrm{N}_{2}$ in $\mathrm{NaCl}$ aqueous solutions lie in between 0.11 and $0.15 \mathrm{~kg} \cdot \mathrm{mol}^{-1}$, and $K_{S}$ values for $\mathrm{SO}_{2}$ range from 0.07 to $0.22 \mathrm{~kg} \cdot \mathrm{mol}^{-1}$. In the 
Table 15: Simulated Henry constants for some gases in $\mathrm{NaCl}$ aqueous solutions for temperatures ranging from $298.15 \mathrm{~K}$ to $373.15 \mathrm{~K}$.

\begin{tabular}{ccccccc}
$\begin{array}{c}\text { Temperature } \\
(\mathrm{K})\end{array}$ & $\mathrm{m}$ & \multicolumn{5}{c}{ Henry constant (MPa.mol/mol) } \\
$\left(\mathrm{mol}^{2} \mathrm{~kg}^{-1}\right)$ & $\mathrm{SO}_{2}$ & $\mathrm{CO}_{2}$ & $\mathrm{NO}$ & $\mathrm{O}_{2}$ & $\mathrm{~N}_{2}$ \\
\hline \multirow{2}{*}{298.15} & 1 & 20 & 548 & 6225 & 7288 & 18861 \\
& 2 & 39 & 744 & 10273 & 11813 & 33861 \\
& 3 & 55 & 909 & 12209 & 14389 & 38511 \\
323.15 & 1 & 48 & 845 & 8222 & 9362 & 23340 \\
& 2 & 64 & 1318 & 11935 & 13672 & 36873 \\
& 3 & 84 & 1295 & 13945 & 15868 & 41267 \\
& 1 & 87 & 1298 & 8683 & 9675 & 21086 \\
& 2 & 102 & 1734 & 11747 & 13177 & 29267 \\
& 3 & 111 & 2248 & 15739 & 17627 & 39944 \\
\hline
\end{tabular}

case of $\mathrm{CaCl}_{2}$ aqueous solutions, simulated $K_{S}$ values range from 0.07 to 0.20 kg.mol ${ }^{-1}$. Considering uncertainties on simulated $K_{H}$ values, simulated $K_{S}$ are in agreement with estimations obtained using the Schumpe and Weisenberger model with predicted $K_{S}$ in between -0.02 and $0.28 \mathrm{~kg} \cdot \mathrm{mol}^{-1}$ for the same systems [88, 89].

\subsection{Solubility of sulphur dioxide in brines}

We propose to supplement information contained in Tables 15 and 16 computing $\mathrm{SO}_{2}$ solubility in $\mathrm{NaCl}$ and $\mathrm{CaCl}_{2}$ aqueous solutions at higher pressure values. For the two investigated temperatures (298.15 K and $323.15 \mathrm{~K}$ ), phase diagrams for the $\mathrm{SO}_{2}+$ brine mixtures exhibit a VL equilibrium domain at the lowest pressures and a liquid-liquid equilibrium domain at the highest pressures, with a three-phase line in between these two domains. MC molecular simulations were performed in the Gibbs ensemble for pressures up to $10 \mathrm{MPa}$, in the Gibbs- $N p T$ ensemble for diphasic systems and in the Gibbs-NVT ensemble for triphasic systems. Note that an additional constraint prevents the transfer of ions from the liquid to the vapour phase. For each MC simulation, the number of generated configurations ranged within $7.10^{8}$ and $8.10^{8}$ including the equi- 
Table 16: Simulated Henry constants for some gases in $\mathrm{CaCl}_{2}$ aqueous solutions for temperatures ranging from $323.15 \mathrm{~K}$ to $373.15 \mathrm{~K}$.

\begin{tabular}{ccccccc}
$\begin{array}{c}\text { Temperature } \\
(\mathrm{K})\end{array}$ & $\mathrm{m}$ & \multicolumn{5}{c}{ Henry constant (MPa.mol/mol) } \\
$\left(\mathrm{mol}^{2} \mathrm{~kg}^{-1}\right)$ & $\mathrm{SO}_{2}$ & $\mathrm{CO}_{2}$ & $\mathrm{NO}$ & $\mathrm{O}_{2}$ & $\mathrm{~N}_{2}$ \\
\hline \multirow{2}{*}{298.15} & 1 & 43 & 643 & 8155 & 9208 & 27339 \\
& 2 & 67 & 942 & 10880 & 12387 & 36286 \\
323.15 & 3 & 72 & 1587 & 18655 & 21145 & 63282 \\
& 1 & 47 & 825 & 8723 & 9861 & 25073 \\
& 2 & 53 & 1237 & 12593 & 14174 & 37067 \\
373.15 & 3 & 60 & 1862 & 15225 & 17495 & 45923 \\
& 1 & 123 & 1533 & 9722 & 10816 & 24196 \\
& 2 & 189 & 2441 & 14181 & 15793 & 36816 \\
& 3 & 253 & 3115 & 18332 & 20281 & 46899 \\
\hline
\end{tabular}

libration of the system and the production run. Table 17 presents simulated phase compositions for $\mathrm{SO}_{2}+$ brines $\left(\mathrm{H}_{2} \mathrm{O} / \mathrm{NaCl}\right.$ and $\mathrm{H}_{2} \mathrm{O} / \mathrm{CaCl}_{2}, 3$ mol.kg $\left.{ }^{-1}\right)$ systems for temperatures in between $298.15 \mathrm{~K}$ and $373.15 \mathrm{~K}$. Table 17 contains information regarding coordinates of the three-phase line in between the vapourliquid and the liquid-liquid equilibrium domains in the case of $\mathrm{NaCl}$ brines. For these systems, obtained three-phase line pressures are similar to pure water cases with $0.40 \mathrm{MPa}$ and $0.89 \mathrm{MPa}$ at $298.15 \mathrm{~K}$ and $323.15 \mathrm{~K}$, respectively. Note that no attempt to capture the three-phase line has been done in the case of $\mathrm{SO}_{2}+\mathrm{H}_{2} \mathrm{O} / \mathrm{CaCl}_{2}$ systems. Using solubility data presented in Table 17 one can estimate Henry constant values of $\mathrm{SO}_{2}$ in a $\mathrm{NaCl}\left(3 \mathrm{~mol} \cdot \mathrm{kg}^{-1}\right)$ aqueous solution: $41 \mathrm{MPa} . \mathrm{mol} / \mathrm{mol}$ at $298.15 \mathrm{~K}$ and $72 \mathrm{MPa} . \mathrm{mol} / \mathrm{mol}$ at $323.15 \mathrm{~K}$, in agreement with values reported in Table 15. Using solubility data presented in Table 17 one can also estimate Henry constant values for $\mathrm{SO}_{2}$ in a $\mathrm{CaCl}_{2}$ (3 mol. $\mathrm{kg}^{-1}$ ) aqueous solutions: $51 \mathrm{MPa} . \mathrm{mol} / \mathrm{mol}$ at $298.15 \mathrm{~K}, 59 \mathrm{MPa} . \mathrm{mol} / \mathrm{mol}$ at $323.15 \mathrm{~K}$ and $257 \mathrm{MPa} . \mathrm{mol} / \mathrm{mol}$ at $373.15 \mathrm{~K}$, in agreement with values reported in Table 16 , 
Table 17: Phase compositions for the $\mathrm{SO}_{2}+$ brine $\left(\mathrm{H}_{2} \mathrm{O} / \mathrm{NaCl}\right.$ and $\mathrm{H}_{2} \mathrm{O} / \mathrm{CaCl}_{2}$, with a salt molal concentration of $3 \mathrm{~mol} . \mathrm{kg}^{-1}$ ) systems at different temperatures, obtained using $\mathrm{MC}$ molecular simulation. $\mathrm{V}$ denotes the vapour phase, and $\mathrm{L} 1$ and $\mathrm{L} 2$ stand for $\mathrm{H}_{2} \mathrm{O}$-rich and $\mathrm{SO}_{2}$-rich liquids, respectively.

\begin{tabular}{|c|c|c|c|c|c|c|c|}
\hline \multirow{2}{*}{$\begin{array}{c}\mathrm{P} \\
(\mathrm{MPa})\end{array}$} & \multicolumn{3}{|c|}{ Molar fraction of $\mathrm{SO}_{2}$} & \multirow{2}{*}{$\begin{array}{c}\mathrm{P} \\
(\mathrm{MPa})\end{array}$} & \multicolumn{3}{|c|}{ Molar fraction of $\mathrm{SO}_{2}$} \\
\hline & $\mathrm{L} 1$ & L2 & $\mathrm{V}$ & & L1 & L2 & $\mathrm{V}$ \\
\hline \multicolumn{4}{|c|}{$\mathrm{H}_{2} \mathrm{O}+\mathrm{NaCl}, 298.15 \mathrm{~K}$} & \multicolumn{4}{|c|}{$\mathrm{H}_{2} \mathrm{O}+\mathrm{CaCl}_{2}, 298.15 \mathrm{~K}$} \\
\hline 0.05 & 0.0012 & - & 0.9862 & 0.05 & 0.0022 & - & 0.9877 \\
\hline 0.10 & 0.0035 & - & 0.9935 & 0.10 & 0.0036 & - & 0.9945 \\
\hline 0.50 & 0.0124 & - & 0.9986 & 0.50 & 0.0112 & - & 0.9986 \\
\hline 0.40 & 0.0107 & 0.9912 & 0.9984 & 1.00 & 0.0321 & 0.9916 & - \\
\hline 1.00 & 0.0198 & 0.9926 & - & & $\mathrm{H}_{2} \mathrm{O}+$ & $\mathrm{l}_{2}, 323$ & \\
\hline 3.00 & 0.0202 & 0.9923 & - & 0.05 & 0.0004 & - & 0.9434 \\
\hline 5.00 & 0.0382 & 0.9878 & - & 0.10 & 0.0014 & - & 0.9725 \\
\hline \multirow[t]{2}{*}{10.00} & 0.0120 & 0.9929 & - & 0.50 & 0.0081 & - & 0.9937 \\
\hline & \multicolumn{3}{|c|}{$\mathrm{H}_{2} \mathrm{O}+\mathrm{NaCl}, 323.15 \mathrm{~K}$} & 1.00 & 0.0268 & 0.9858 & - \\
\hline 0.05 & 0.0008 & - & 0.9407 & & $\mathrm{H}_{2} \mathrm{O}+$ & $\mathrm{l}_{2}, 373$ & \\
\hline 0.10 & 0.0013 & - & 0.9699 & 0.05 & 0.0001 & - & 0.3737 \\
\hline 0.50 & 0.0074 & - & 0.9932 & 0.10 & 0.0003 & - & 0.6724 \\
\hline 0.89 & 0.0123 & 0.9844 & 0.9960 & 0.50 & 0.0018 & - & 0.9321 \\
\hline 1.00 & 0.0135 & 0.9846 & - & 1.00 & 0.0157 & 0.9604 & - \\
\hline 3.00 & 0.0132 & 0.9856 & - & & & & \\
\hline 5.00 & 0.0133 & 0.9849 & - & & & & \\
\hline 10.00 & 0.0101 & 0.9843 & - & & & & \\
\hline
\end{tabular}




\section{Conclusions}

In the present work, we have proposed new insights for $\mathrm{NO}+\mathrm{SO}_{2}$ binary systems, using molecular simulation techniques, equations of state, and experiments. Using intermolecular potentials available in the literature we have demonstrated the capability of molecular simulation techniques in predicting properties for mixtures. Solubilities of some gases $\left(\mathrm{CO}_{2}\right.$ and associated gases such as $\mathrm{O}_{2}, \mathrm{~N}_{2}, \mathrm{SO}_{2}, \mathrm{NO}$ ) in water and in $\mathrm{NaCl}$ and $\mathrm{CaCl}_{2}$ aqueous solutions have also been studied using molecular simulation techniques. In the case of the highest soluble gases (e.g., sulphur dioxide) reasonable simulation box size can be envisaged and explicit analysis of phase compositions performed. For gas with low solubility value $\left(\mathrm{CO}_{2}, \mathrm{O}_{2}, \mathrm{~N}_{2}\right.$, and $\left.\mathrm{NO}\right)$ we only determined Henry constants.

Results of performed quantum chemical calculations tend to indicate no favoured chemical reaction between $\mathrm{NO}$ and $\mathrm{SO}_{2}$ in the gas phase. In addition, no evidence of such chemical reaction has been observed during the experimental data acquisition. New sets of experimental vapour compositions have been proposed for $\mathrm{NO}+\mathrm{SO}_{2}$ binary mixtures. Data generated using molecular simulations agree fairly well with reference experimental data. Using the so-obtained data, we proposed new sets of parameters for the PPR78 EoS model. Henry constant values for gases in water generated by means of molecular simulations fairly agree with reference data. The performed study on the ability of various potentials in predicting sodium chloride and calcium chloride brine densities and osmotic pressures led us to recommend two sets of parameters, both involving the TIP4P/2005 water potential. Finally, Henry constant values for gases in sodium chloride and calcium chloride brines were generated by means of molecular simulations.

In this work, we show that combining some experiments, molecular simulations and equation of state modelling is relevant to fill the lack of information for gas mixtures representative of systems encountered in CCS operations. Using validated intermolecular potentials, molecular simulations is an interesting 
687

tool to generate data, especially when hazardous compounds and/or extreme pressure or temperature conditions are considered. Simulated data can then be used to optimize equations of state parameters, and thus to improve models implemented within geochemical codes.

\section{Acknowledgement}

The financial support from the French Agence Nationale de la Recherche, ANR, for the SIGARRR project (ANR-13-SEED-006) is gratefully acknowledged. Authors would like to thank Dr Bernard Rousseau for the use of the NEWTON Molecular Dynamics code. 


\section{References}

[1] United Nation Framework Convention on Climate Change, Adoption of the Paris Agreement, Technical Report, 2015.

[2] A. Torvanger, M. T. Lund, N. Rive, Carbon capture and storage deployment rates: needs and feasibility, Mitigation and Adaptation Strategies for Global Change 18 (2013) 187-205.

[3] S. Thibeau, P. Chiquet, G. Mouronval, M. Lescanne, Geochemical assessment of the injection of $\mathrm{CO}_{2}$ into rousse depleted gas reservoir, Energy Procedia 1 (2009) 3383-3390.

[4] M. Lescanne, J. Hy-Billiot, N. Aimard, C. Prinet, The site monitoring of the Lacq industrial CCS reference project, Energy Procedia 4 (2011) $3518-3525$.

[5] B. Garcia, J. Hy-Billiot, V. Rouchon, G. Mouronval, M. Lescanne, V. Lachet, N. Aimard, A geochemical approach for monitoring a $\mathrm{CO}_{2}$ pilot site: Rousse, france. a major gases, $\mathrm{CO}_{2}$ - carbon isotopes and noble gases combined approach, Oil \& Gas Science and Technology - Revue d'IFP Energies nouvelles 67 (2012) 341-353.

[6] B. Creton, T. d. Bruin, D. Le Roux, P. Duchet-Suchaux, V. Lachet, Impact of associated gases on equilibrium and transport properties of a $\mathrm{CO}_{2}$ stream: Molecular simulation and experimental studies, International Journal of Thermophysics 35 (2014) 256-276.

[7] J. Sterpenich, J. Dubessy, J. Pironon, S. Renard, M.-C. Caumon, A. Randi, J.-N. Jaubert, E. Favre, D. Roizard, M. Parmentier, M. Azaroual, V. Lachet, B. Creton, T. Parra, E. E. Ahmar, C. Coquelet, V. Lagneau, J. Corvisier, P. Chiquet, Role of impurities on $\mathrm{CO}_{2}$ injection: Experimental and numerical simulations of thermodynamic properties of water-salt-gas mixtures $\left(\mathrm{CO}_{2}+\right.$ co-injected gases $)$ under geological storage conditions, Energy Procedia 37 (2013) 3638-3645. 
[8] J. Corvisier, E. E. Ahmar, C. Coquelet, J. Sterpenich, R. Privat, J.-N. Jaubert, K. Ballerat-Busserolles, J.-Y. Coxam, P. Cézac, F. Contamine, J.-P. Serin, V. Lachet, B. Creton, M. Parmentier, P. Blanc, L. André, L. d. Lary, E. C. Gaucher, Simulations of the impact of co-injected gases on $\mathrm{CO}_{2}$ storage, the SIGARRR project: First results on water-gas interactions modeling, Energy Procedia 63 (2014) 3160-3171.

[9] J. Corvisier, M. Hajiw, E. El Ahmar, C. Coquelet, J. Sterpenich, R. Privat, J.-N. Jaubert, K. Ballerat-Busserolles, J.-Y. Coxam, P. Cézac, F. Contamine, J.-P. Serin, V. Lachet, B. Creton, M. Parmentier, J. Tremosa, P. Blanc, L. André, L. de Lary, E. Gaucher, Simulations of the impact of co-injected gases on $\mathrm{CO}_{2}$ storage, the SIGARRR project: Processes and geochemical approaches for gas-water-salt interactions modeling, Energy Procedia 114 (2017) 3322-3334. 13th International Conference on Greenhouse Gas Control Technologies, GHGT-13, 14-18 November 2016, Lausanne, Switzerland.

[10] A. Estublier, P. Bachaud, A. Michel, N. Maurand, J.-P. Deflandre, Longterm fate of $\mathrm{CO}_{2}$ in a saline aquifer: modeling issues, Energy Procedia 63 (2014) 3464-3474.

[11] C. Haase, A. Dahmke, M. Ebert, D. Schäfer, F. Dethlefsen, Suitability of existing numerical model codes and thermodynamic databases for the prognosis of calcite dissolution processes in near-surface sediments due to a $\mathrm{CO}_{2}$ leakage investigated by column experiments, Aquatic Geochemistry 20 (2014) 639-661.

[12] C. Haase, M. Ebert, F. Dethlefsen, Uncertainties of geochemical codes and thermodynamic databases for predicting the impact of carbon dioxide on geologic formations, Applied Geochemistry 67 (2016) 81-92.

[13] D.-Y. Peng, D. B. Robinson, A new two-constant equation of state, Industrial \& Engineering Chemistry Fundamentals 15 (1976) 59-64. 
[14] H. Li, J. P. Jakobsen, Ø. Wilhelmsen, J. Yan, Pvtxy properties of $\mathrm{CO}_{2}$ mixtures relevant for $\mathrm{CO}_{2}$ capture, transport and storage: Review of available experimental data and theoretical models, Applied Energy 88 (2011) 3567-3579.

[15] H. Li, Ø. Wilhelmsen, Y. Lv, W. Wang, J. Yan, Viscosities, thermal conductivities and diffusion coefficients of $\mathrm{CO}_{2}$ mixtures: Review of experimental data and theoretical models, International Journal of Greenhouse Gas Control 5 (2011) 1119-1139.

[16] X. Xu, R. Privat, J.-N. Jaubert, Addition of the sulfur dioxide group $\left(\mathrm{SO}_{2}\right)$, the oxygen group $\left(\mathrm{O}_{2}\right)$, and the nitric oxide group (NO) to the E-PPR78 model, Industrial \& Engineering Chemistry Research 54 (2015) 9494-9504.

[17] X. Xu, R. Privat, J.-N. Jaubert, V. Lachet, B. Creton, Phase equilibrium of CCS mixtures: Equation of state modeling and monte carlo simulation, The Journal of Supercritical Fluids 119 (2017) 169-202.

[18] E. Bourasseau, V. Lachet, N. Desbiens, J.-B. Maillet, J.-M. Teuler, P. Ungerer, Thermodynamic behavior of the $\mathrm{CO}_{2}+\mathrm{NO}_{2} / \mathrm{N}_{2} \mathrm{O}_{4}$ mixture: a monte carlo simulation study, The Journal of Physical Chemistry B 112 (2008) 15783-15792.

[19] V. Lachet, T. de Bruin, P. Ungerer, C. Coquelet, A. Valtz, V. Hasanov, F. Lockwood, D. Richon, Thermodynamic behavior of the $\mathrm{CO}_{2}+\mathrm{SO}_{2}$ mixture: Experimental and monte carlo simulation studies, Energy Procedia 1 (2009) 1641-1647.

[20] E. El Ahmar, B. Creton, A. Valtz, C. Coquelet, V. Lachet, D. Richon, P. Ungerer, Thermodynamic study of binary systems containing sulphur dioxide: Measurements and molecular modelling, Fluid Phase Equilibria 304 (2011) 21-34.

[21] V. Lachet, B. Creton, T. de Bruin, E. Bourasseau, N. Desbiens, Ø. Wilhelmsen, M. Hammer, Equilibrium and transport properties of $\mathrm{CO}_{2}+\mathrm{N}_{2} \mathrm{O}$ 
and $\mathrm{CO}_{2}+\mathrm{NO}$ mixtures: Molecular simulation and equation of state modelling study, Fluid Phase Equilibria 322-323 (2012) 66-78.

[22] C. Coquelet, A. Valtz, P. Arpentinier, Thermodynamic study of binary and ternary systems containing $\mathrm{CO}_{2}+$ impurities in the context of $\mathrm{CO}_{2}$ transportation, Fluid Phase Equilibria 382 (2014) 205-211.

[23] ARMINES, Patent no fr 2853 414, procédé et dispositif pour prélever des micro échantillons d'un fluide sous pression contenu dans un container, 2003.

[24] S. Lasala, P. Chiesa, R. Privat, J.-N. Jaubert, VLE properties of $\mathrm{CO}_{2}$-based binary systems containing $\mathrm{N}_{2}, \mathrm{O}_{2}$ and Ar: Experimental measurements and modelling results with advanced cubic equations of state, Fluid Phase Equilibria 428 (2016) 18-31.

[25] S. Lasala, P. Chiesa, R. Privat, J.-N. Jaubert, Measurement and prediction of multi-property data of $\mathrm{CO}_{2}-\mathrm{N}_{2}-\mathrm{O}_{2}-\mathrm{CH}_{4}$ mixtures with the PengRobinson +residual Helmholtz energy-based model, Fluid Phase Equilibria 437 (2017) 166-180.

[26] S. Lasala, P. Chiesa, R. Privat, J.-N. Jaubert, Modeling the thermodynamics of fluids treated by $\mathrm{CO}_{2}$ capture processes with Peng-Robinson +residual Helmholtz energy-based mixing rules, Industrial \& Engineering Chemistry Research 56 (2017) 2259-2276.

[27] Y. Le Guennec, S. Lasala, R. Privat, J.-N. Jaubert, A consistency test for $\alpha$-functions of cubic equations of state, Fluid Phase Equilibria 427 (2016) $513-538$.

[28] Y. Le Guennec, R. Privat, J.-N. Jaubert, Development of the translatedconsistent tc-pr and tc-rk cubic equations of state for a safe and accurate prediction of volumetric, energetic and saturation properties of pure compounds in the sub- and super-critical domains, Fluid Phase Equilibria 429 (2016) 301-312. 
[29] Y. Le Guennec, R. Privat, S. Lasala, J.-N. Jaubert, On the imperative need to use a consistent $\alpha$-function for the prediction of pure-compound supercritical properties with a cubic equation of state, Fluid Phase Equilibria 445 (2017) 45- 53.

[30] J.-N. Jaubert, R. Privat, Y. Le Guennec, L. Coniglio, Note on the properties altered by application of a péneloux-type volume translation to an equation of state, Fluid Phase Equilibria 419 (2016) 88-95.

[31] R. Privat, J.-N. Jaubert, Y. Le Guennec, Incorporation of a volume translation in an equation of state for fluid mixtures: which combining rule? which effect on properties of mixing?, Fluid Phase Equilibria 427 (2016) 414-420.

[32] X. Xu, S. Lasala, R. Privat, J.-N. Jaubert, E-PPR78: A proper cubic EoS for modelling fluids involved in the design and operation of carbon dioxide capture and storage (CCS) processes, International Journal of Greenhouse Gas Control 56 (2017) 126-154.

[33] J.-N. Jaubert, F. Mutelet, VLE predictions with the Peng-Robinson equation of state and temperature dependent kij calculated through a group contribution method, Fluid Phase Equilibria 224 (2004) 285-304.

[34] J.-W. Qian, R. Privat, J.-N. Jaubert, Predicting the phase equilibria, critical phenomena, and mixing enthalpies of binary aqueous systems containing alkanes, cycloalkanes, aromatics, alkenes, and gases $\left(\mathrm{N}_{2}, \mathrm{CO}_{2}, \mathrm{H}_{2} \mathrm{~S}, \mathrm{H}_{2}\right)$ with the PPR78 equation of state, Industrial \& Engineering Chemistry Research 52 (2013) 16457-16490.

[35] P. Ungerer, B. Tavitian, A. Boutin, Applications of Molecular Simulation in the Oil and Gas Industry - Monte-Carlo Methods, Editions TECHNIP, 2005.

[36] A. Z. Panagiotopoulos, Direct determination of phase coexistence prop- 
erties of fluids by Monte Carlo simulation in a new ensemble, Molecular Physics 61 (1987) 813-826.

[37] A. Panagiotopoulos, N. Quirke, M. Stapleton, D. J. Tildesley, Phase equilibria by simulation in the Gibbs ensemble, Molecular Physics 63 (1988) $527-545$.

[38] S. Duane, A. Kennedy, B. J. Pendleton, D. Roweth, Hybrid Monte Carlo, Physics Letters B 195 (1987) 216-222.

[39] V. Lachet, J.-M. Teuler, B. Rousseau, Classical force field for hydrofluorocarbon molecular simulations. application to the study of gas solubility in poly(vinylidene fluoride), The Journal of Physical Chemistry A 119 (2015) $140-151$.

[40] N.-T. Van-Oanh, C. Houriez, B. Rousseau, Viscosity of the 1-ethyl3-methylimidazolium bis(trifluoromethylsulfonyl)imide ionic liquid from equilibrium and nonequilibrium molecular dynamics, Physical Chemistry Chemical Physics 12 (2010) 930-936.

[41] Y. Luo, B. Roux, Simulation of osmotic pressure in concentrated aqueous salt solutions, The Journal of Physical Chemistry Letters 1 (2010) 183-189.

[42] J. G. Harris, K. H. Yung, Carbon dioxide's liquid-vapor coexistence curve and critical properties as predicted by a simple molecular model, The Journal of Physical Chemistry 99 (1995) 12021-12024.

[43] J. Delhommelle, Etablissement de potentiels d'interactions pour la simulation moléculaire. Application à la prédiction des équilibres liquide-vapeur de mélanges binaires alcane-molécule multipolaire, Ph.D. Thesis, Université Paris XI, Orsay, France, 2000.

[44] J. Vrabec, J. Stoll, H. Hasse, A set of molecular models for symmetric quadrupolar fluids, The Journal of Physical Chemistry B 105 (2001) 1212612133. 
[45] Y. Boutard, P. Ungerer, J. M. Teuler, M. G. Ahunbay, S. F. Sabater, J. Pérez-Pellitero, A. D. Mackie, E. Bourasseau, Extension of the anisotropic united atoms intermolecular potential to amines, amides and alkanols, Fluid Phase Equilibria 236 (2005) 25-41.

[46] H. J. C. Berendsen, J. R. Grigera, T. P. Straatsma, The missing term in effective pair potentials, The Journal of Physical Chemistry 91 (1987) 6269-6271.

[47] J. L. F. Abascal, C. Vega, A general purpose model for the condensed phases of water: TIP4P/2005, The Journal of Chemical Physics 123 (2005) 234505.

[48] C. Nieto-Draghi, T. de Bruin, J. Pérez-Pellitero, J. Bonet Avalos, A. D. Mackie, Thermodynamic and transport properties of carbon dioxide from molecular simulation, The Journal of Chemical Physics 126 (2007) 064509.

[49] B. Guillot, A reappraisal of what we have learnt during three decades of computer simulations on water, Journal of Molecular Liquids 101 (2002) 219-260.

[50] L. Vlcek, A. A. Chialvo, D. R. Cole, Optimized unlike-pair interactions for water-carbon dioxide mixtures described by the SPC/E and EPM2 models, The Journal of Physical Chemistry B 115 (2011) 8775-8784.

[51] C. Vega, J. L. F. Abascal, Simulating water with rigid non-polarizable models: a general perspective, Physical Chemistry Chemical Physics 13 (2011) 19663?19688.

[52] R. Sakamaki, A. K. Sum, T. Narumi, K. Yasuoka, Molecular dynamics simulations of vapor/liquid coexistence using the nonpolarizable water models, The Journal of Chemical Physics 134 (2011) 124708.

[53] V. Vinš, D. Celný, B. Planková, T. Němec, M. Duška, J. Hrubý, P. Dančová, M. Veselý, Molecular simulations of the vapor-liquid phase 
interfaces of pure water modeled with the SPC/E and the TIP4P/2005 molecular models, EPJ Web of Conferences 114 (2016) 02136.

[54] J. Chandrasekhar, D. C. Spellmeyer, W. L. Jorgensen, Energy component analysis for dilute aqueous solutions of lithium(1+), sodium(1+), fluoride(1-), and chloride(1-) ions, Journal of the American Chemical Society 106 (1984) 903-910.

[55] W. L. Jorgensen, D. S. Maxwell, J. Tirado-Rives, Development and testing of the OPLS all-atom force field on conformational energetics and properties of organic liquids, Journal of the American Chemical Society 118 (1996) $11225-11236$.

[56] D. R. Wheeler, J. Newman, Molecular dynamics simulations of multicomponent diffusion. 1. equilibrium method, The Journal of Physical Chemistry B 108 (2004) 18353-18361.

[57] G. H. Goo, G. Sung, S. H. Lee, Molecular dynamics simulation studies of the limiting conductances of $\mathrm{MgCl}_{2}$ and $\mathrm{CaCl}_{2}$ in supercritical water using SPC/E model for water, Molecular Simulation 30 (2004) 37-44.

[58] J. Áqvist, Ion-water interaction potentials derived from free energy perturbation simulations, The Journal of Physical Chemistry 94 (1990) 80218024 .

[59] M. M. Reif, P. H. Hünenberger, Computation of methodology-independent single-ion solvation properties from molecular simulations. IV. optimized lennard-jones interaction parameter sets for the alkali and halide ions in water, The Journal of Chemical Physics 134 (2011) 144104.

[60] J.-C. Neyt, A. Wender, V. Lachet, A. Ghoufi, P. Malfreyt, Prediction of the concentration dependence of the surface tension and density of salt solutions: atomistic simulations using drude oscillator polarizable and nonpolarizable models, Physical Chemistry Chemical Physics 15 (2013) 1167911690. 
[61] J.-C. Neyt, A. Wender, V. Lachet, A. Szymczyk, A. Ghoufi, P. Malfreyt, How does the electronic continuum model perform in the prediction of the surface tension of salt solutions?, Chemical Physics Letters 595-596 (2014) 209-213.

[62] G. A. Orozco, O. A. Moultos, H. Jiang, I. G. Economou, A. Z. Panagiotopoulos, Molecular simulation of thermodynamic and transport properties for the $\mathrm{H}_{2} \mathrm{O}+\mathrm{NaCl}$ system, The Journal of Chemical Physics 141 (2014) 234507.

[63] E. S. Tsai, H. Jiang, A. Z. Panagiotopoulos, Monte carlo simulations of $\mathrm{H}_{2} \mathrm{O}-\mathrm{CaCl}_{2}$ and $\mathrm{H} 2 \mathrm{O}-\mathrm{CaCl}_{2}-\mathrm{CO}_{2}$ mixtures, Fluid Phase Equilibria 407 (2016) 262-268.

[64] R. P. Matthews, K. J. Naidoo, Experimentally consistent ion association predicted for metal solutions from free energy simulations, The Journal of Physical Chemistry B 114 (2010) 7286-7293.

[65] L. X. Dang, D. E. Smith, Comment on "mean force potential for the calcium-chloride ion pair in water" [j. chem. phys. 99, 4229 (1993)], The Journal of Chemical Physics 102 (1995) 3483.

[66] L. X. Dang, Mechanism and thermodynamics of ion selectivity in aqueous solutions of 18-crown-6 ether: A molecular dynamics study, Journal of the American Chemical Society 117 (1995) 6954-6960.

[67] M. Předota, Z. Zhang, P. Fenter, D. J. Wesolowski, P. T. Cummings, Electric double layer at the rutile (110) surface. 2. adsorption of ions from molecular dynamics and X-ray experiments, The Journal of Physical Chemistry B 108 (2004) 12061-12072.

[68] M. J. Frisch, G. W. Trucks, H. B. Schlegel, G. E. Scuseria, M. A. Robb, Cheeseman, G. Scalmani, V. Barone, B. Mennucci, G. A. Petersson, H. Nakatsuji, M. Caricato, X. Li, H. P. Hratchian, Izmaylov, A. F., 
J. Bloino, G. Zheng, Sonnenberg, J. L., M. Hada, M. Ehara, K. Toyota, R. Fukuda, J. Hasegawa, M. Ishida, T. Nakajima, Y. Honda, O. Kitao, H. Nakai, T. Vreven, J. A. Montgomery, Peralta, J. E., F. Ogliaro, M. Bearpark, Heyd, J. J., E. Brothers, K. N. Kudin, Staroverov, V. N., R. Kobayashi, J. Normand, K. Raghavachari, A. Rendell, J. C. Burant, S. S. Iyengar, J. Tomasi, M. Cossi, N. Rega, J. M. Millam, M. Klene, J. E. Knox, J. B. Cross, V. Bakken, C. Adamo, J. Jaramillo, R. Gomperts, R. E. Stratmann, O. Yazyev, A. J. Austin, R. Cammi, C. Pomelli, J. W. Ochterski, R. L. Martin, K. Morokuma, V. G. Zakrzewski, G. A. Voth, P. Salvador, J. J. Dannenberg, S. Dapprich, A. D. Daniels, Farkas, J. B. Foresman, J. V. Ortiz, J. Cioslowski, D. J. Fox, Gaussian 09, revision b.01, Gaussian 09, Revision B.01, Gaussian, Inc., Wallingford CT (2009).

[69] Y. Zhao, D. G. Truhlar, The M06 suite of density functionals for main group thermochemistry, thermochemical kinetics, noncovalent interactions, excited states, and transition elements: two new functionals and systematic testing of four M06-class functionals and 12 other function, Theoretical Chemistry Accounts 120 (2007) 215-241.

[70] M. Tobita, S. Perera, M. Musial, R. Bartlett, M. Nooijen, J. Lee, Critical comparison of single-reference and multireference coupled-cluster methods: Geometry, harmonic frequencies, and excitation energies of $\mathrm{N}_{2} \mathrm{O}_{2}$, The Journal of Chemical Physics 119 (2003) 10713-10723.

[71] R. Sayós, R. Valero, J. Anglada, M. González, Theoretical investigation of the eight low-lying electronic states of the cis- and trans-nitric oxide dimers and its isomerization using multiconfigurational second-order perturbation theory (CASPT2), The Journal of Chemical Physics 112 (2000) 6608-6624.

[72] A. Dkhissi, P. Soulard, A. Perrin, N. Lacome, The 5NO6 dimer, Journal of Molecular Spectroscopy 183 (1997) 12-17.

[73] A. McKellar, J. Watson, B. Howard, The NO dimer: $15 \mathrm{~N}$ isotopic infrared spectra, line-widths, and force field, Molecular Physics 86 (1995) 273-286. 
[74] M. P. Allen, D. J. Tildesley, Computer simulation of liquids, Oxford Science Publications, Oxford, 1987.

[75] R. Privat, J.-N. Jaubert, Classification of global fluid-phase equilibrium behaviors in binary systems, Chemical Engineering Research and Design 91 (2013) 1807-1839.

[76] P. Van Konynenburg, R. Scott, Critical lines and phase equilibria in binary van der waals mixtures, Philosophical Transactions of the Royal Society: Mathematical, Physical and Engineering Sciences 298 (1980) 495-540.

[77] M. Michelsen, A modified Huron-Vidal mixing rule for cubic equations of state, Fluid Phase Equilibria 60 (1990) 213-219.

[78] M. Lísal, W. R. Smith, K. Aim, Analysis of Henry's constant for carbon dioxide in water via Monte Carlo simulation, Fluid Phase Equilibria 226 (2004) 161-172.

[79] G. A. Orozco, V. Lachet, A. D. Mackie, Physical absorption of green house gases in amines: The influence of functionality, structure, and crossinteractions, The Journal of Physical Chemistry B 120 (2016) 13136-13143.

[80] J. J. Carroll, J. D. Slupsky, A. E. Mather, The solubility of carbon dioxide in water at low pressure, Journal of Physical and Chemical Reference Data 20 (1991) 1201-1209.

[81] A. Harvey, Semiempirical correlation for henry's constants over large temperature ranges, AIChE Journal 42 (1996) 1491-1494.

[82] C. L. Yaws, Chemical properties handbook: physical, thermodynamic, environmental transport, safety, and health related properties for organic and inorganic chemicals, McGraw-Hill, New York, USA, 1999.

[83] H.-L. Zhang, S.-J. Han, Viscosity and density of water + sodium chloride + potassium chloride solutions at $298.15 \mathrm{~K}$, Journal of Chemical \& Engineering Data 41 (1996) 516-520. 
[84] G. Wilczek-Vera, J. H. Vera, How much do we know about the activity of individual ions?, The Journal of Chemical Thermodynamics 99 (2016) 65-69.

[85] B. Staples, R. Nuttall, The activity and osmotic coefficients of aqueous calcium chloride at 298.15 K, Journal of Physical and Chemical Reference Data 6 (1977) 385-408.

[86] I. M. Sechenov, Über die konstitution der salzlösungen auf grund ihres verhaltens zu kohlensäurethe solubility of carbon dioxide in water at low pressure, Zeitschrift fr Physikalische Chemie 4 (1889) 117-125.

[87] S. K. Saxena, Advances in Physical Geochemistry, vol. 2, Springer New York, 1982.

[88] A. Schumpe, The estimation of gas solubilities in salt solutions, Chemical Engineering Science 48 (1993) 153-158.

[89] S. Weisenberger, A. Schumpe, Estimation of gas solubilities in salt solutions at temperatures from $273 \mathrm{~K}$ to $363 \mathrm{~K}$, AIChE Journal 42 (1996) 298-300.

[90] W. B. Campbell, O. Maass, Equilibria in sulfur dioxide solutions, Canadian Journal of Research, Section B 2 (1930) 42-64.

[91] T. K. Sherwood, Solubilities of sulfur dioxide and ammonia in water, Industrial \& Engineering Chemistry 17 (1925) 745-747.

[92] B. Rumpf, G. Maurer, Solubilities of hydrogen cyanide and sulfur dioxide in water at temperatures from 293.15 to $413.15 \mathrm{~K}$ and pressures up to 2.5 MPa, Fluid Phase Equilibria 81 (1992) 241-260.

[93] S. G. Sayegh, J. Najman, $\mathrm{CO}_{2}-\mathrm{SO}_{2}$ brine phase behavior studies, Report (1984).

[94] H.-L. Zhang, G.-H. Chen, S.-J. Han, Viscosity and density of $\mathrm{H}_{2} \mathrm{O}+\mathrm{NaCl}+\mathrm{CaCl}_{2}$ and $\mathrm{H}_{2} \mathrm{O}+\mathrm{KCl}+\mathrm{CaCl}_{2}$ at $298.15 \mathrm{~K}$, Journal of Chemical \& Engineering Data 42 (1997) 526-530. 


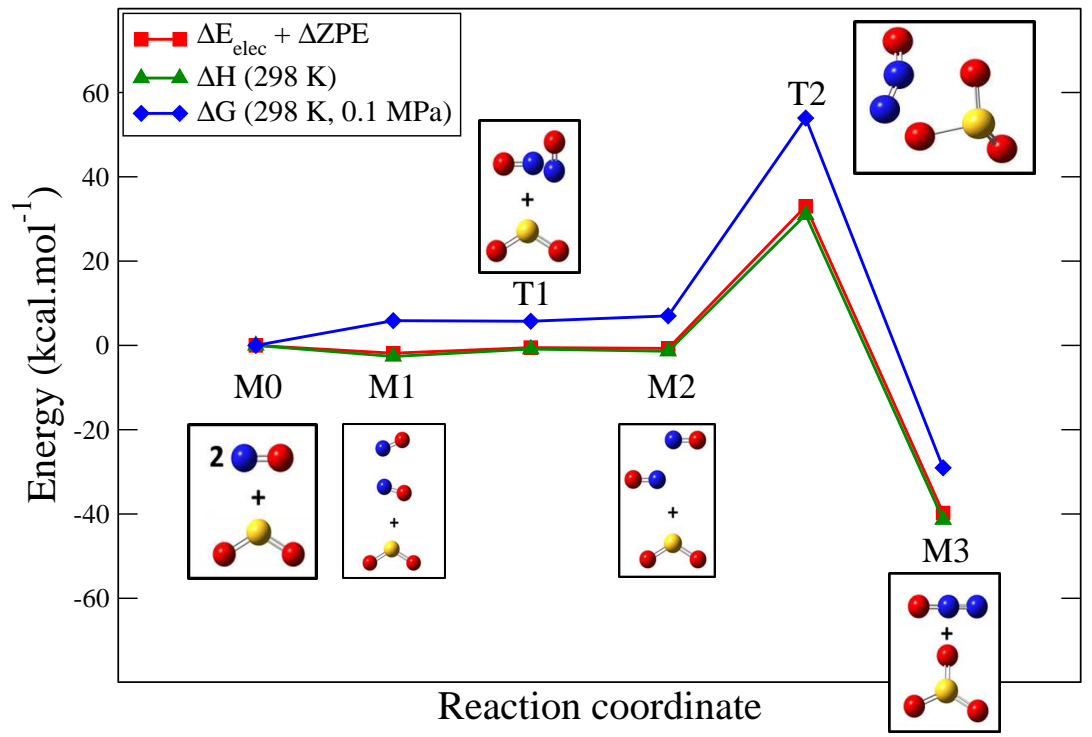

Figure 1: Energy profiles for the $\mathrm{SO}_{2}+2 \mathrm{NO} \rightleftharpoons \mathrm{SO}_{3}+\mathrm{N}_{2} \mathrm{O}$ reaction for the electronic energy corrected for the zero point energy (red), the enthalpy at $\mathrm{T}=298 \mathrm{~K}$ (green) and the Gibbs energy at $\mathrm{T}=298 \mathrm{~K}$ and $\mathrm{P}=0.1 \mathrm{MPa}$ (blue). 


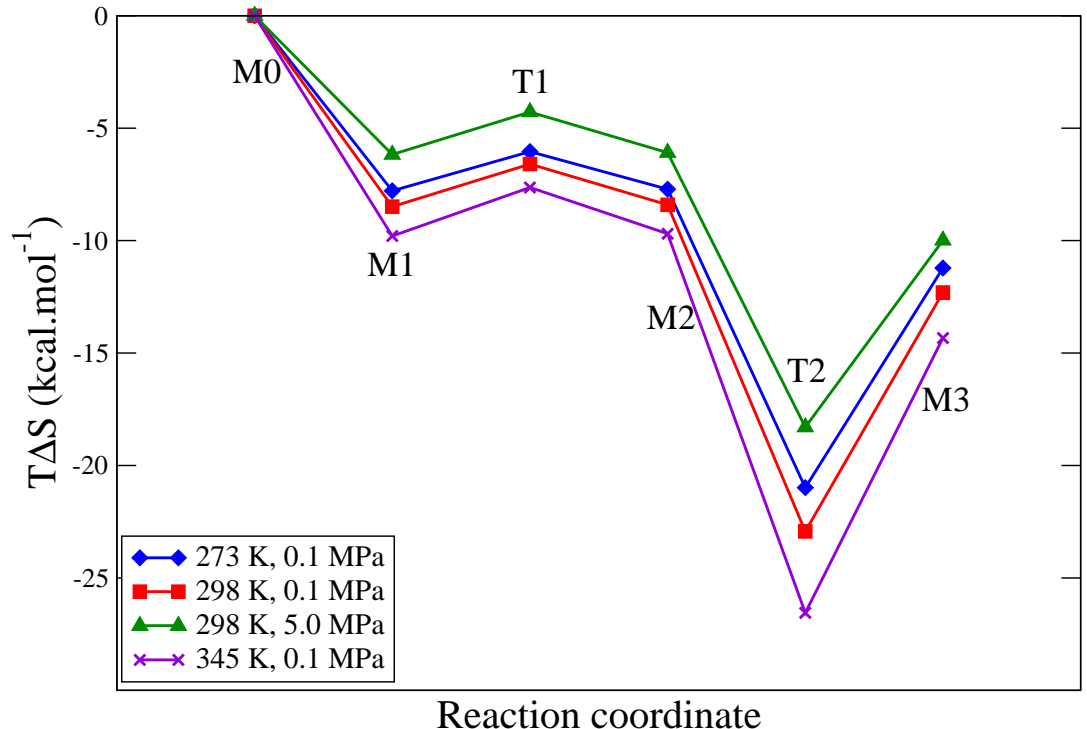

Figure 2: Changes (in kcal.mol ${ }^{-1}$ ) of $\mathrm{T} \Delta \mathrm{S}$ as a function of the reaction coordinate with respect to M0, for 3 temperatures and 2 pressures. 


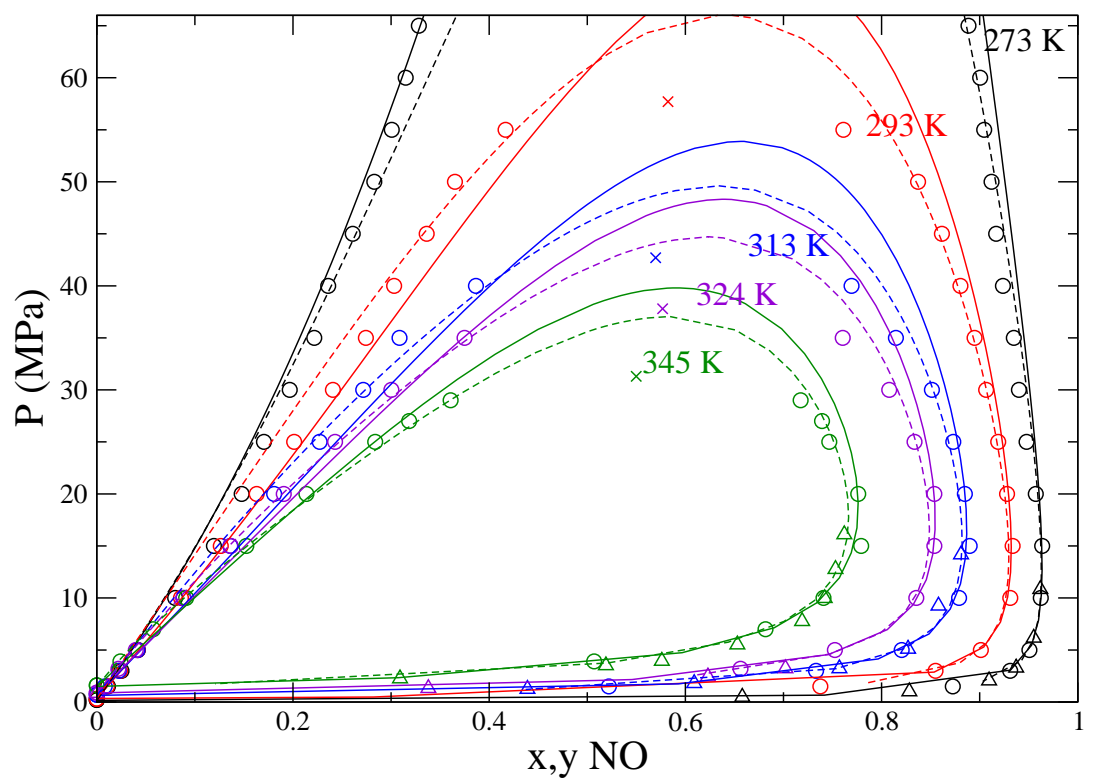

Figure 3: $(P, \mathrm{x}, \mathrm{y})$ phase diagrams for the $\mathrm{NO}+\mathrm{SO}_{2}$ at five temperatures: $273 \mathrm{~K}$ (black), 293 $\mathrm{K}$ (red), $313 \mathrm{~K}$ (blue), $324 \mathrm{~K}$ (purple), and $345 \mathrm{~K}$ (green). Triangles stand for experimental data (this work and data cited in [16]). Circles denote data obtained using MC molecular simulations, and crosses represent critical points estimated using equations (9) and (10). Lines represent predictions obtained using the PR EoS together with the van Laar model (solid line) and the PR EoS together with the residual part of the Wilson model (dashed line). 


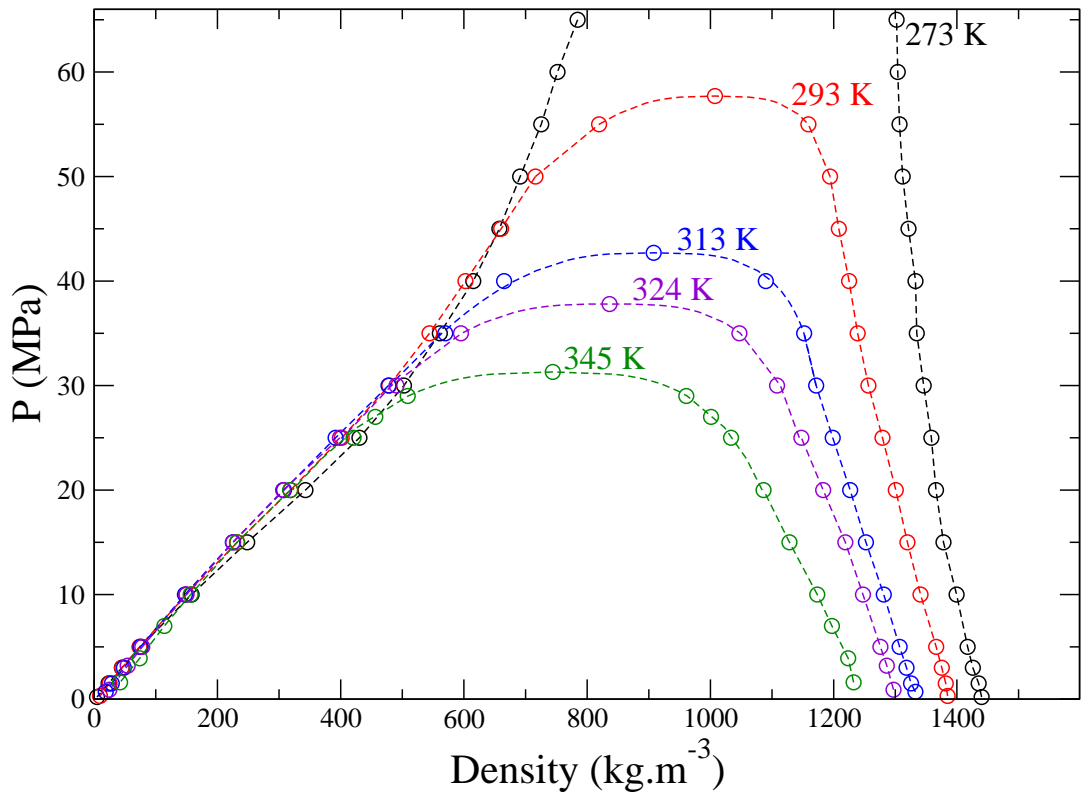

Figure 4: Pressure-density diagrams drawn using data obtained by $\mathrm{MC}$ molecular simulations, for the $\mathrm{NO}+\mathrm{SO}_{2}$ at five temperatures: $273 \mathrm{~K}, 293 \mathrm{~K}, 313 \mathrm{~K}, 324 \mathrm{~K}$, and $345 \mathrm{~K}$. 


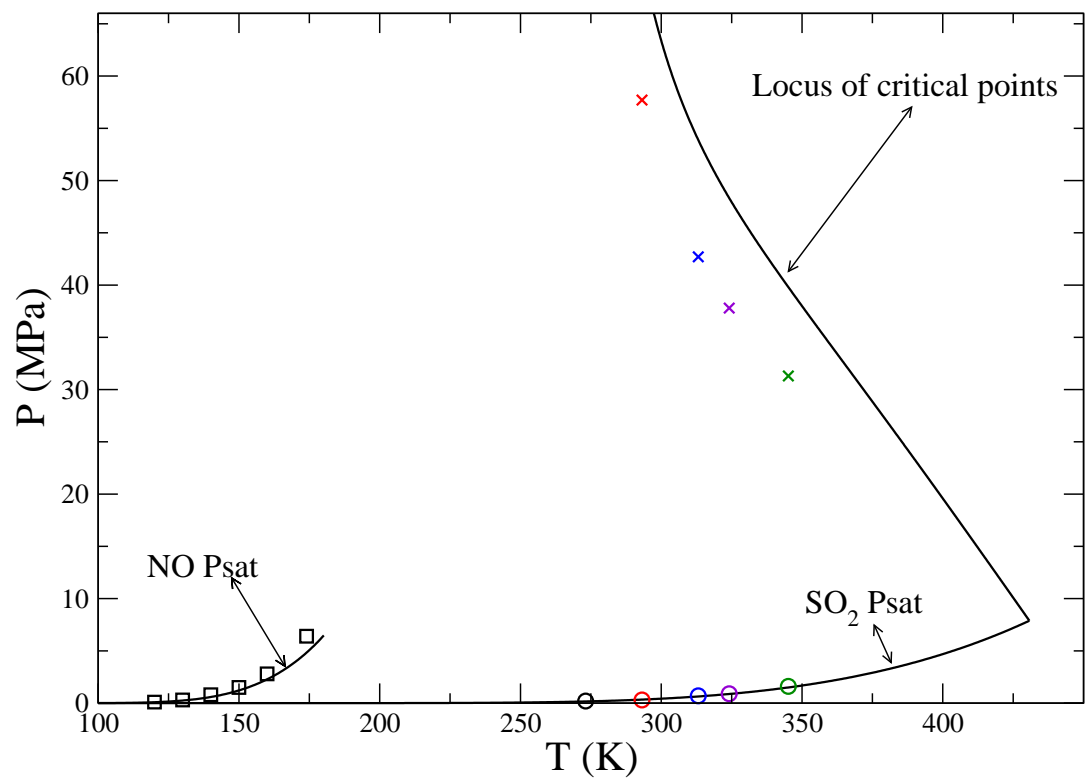

Figure 5: Global pressure-temperature diagram for the $\mathrm{NO}+\mathrm{SO}_{2}$. Lines represent predictions using the PR EoS with the the van Laar model, and symbols stands for data obtained using MC molecular simulations at five temperatures: $273 \mathrm{~K}$ (black), $293 \mathrm{~K}$ (red), $313 \mathrm{~K}$ (blue), $324 \mathrm{~K}$ (purple), and $345 \mathrm{~K}$ (green). NO data for vapour pressure (squares) obtained by MC simulations are taken from our previous work [21]. 


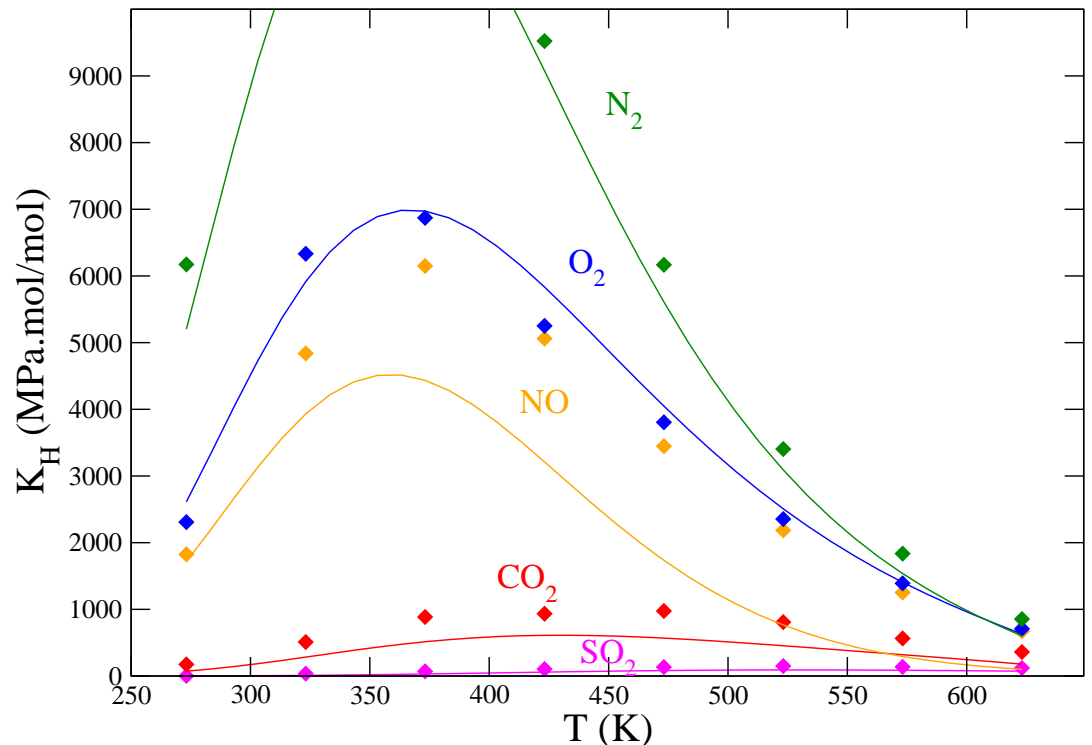

Figure 6: Comparison of simulated Henry constants (diamonds) for $\mathrm{SO}_{2}, \mathrm{CO}_{2}, \mathrm{NO}, \mathrm{O}_{2}$, and $\mathrm{N}_{2}$ in water, and corresponding curve fitting of experimental values (lines). 


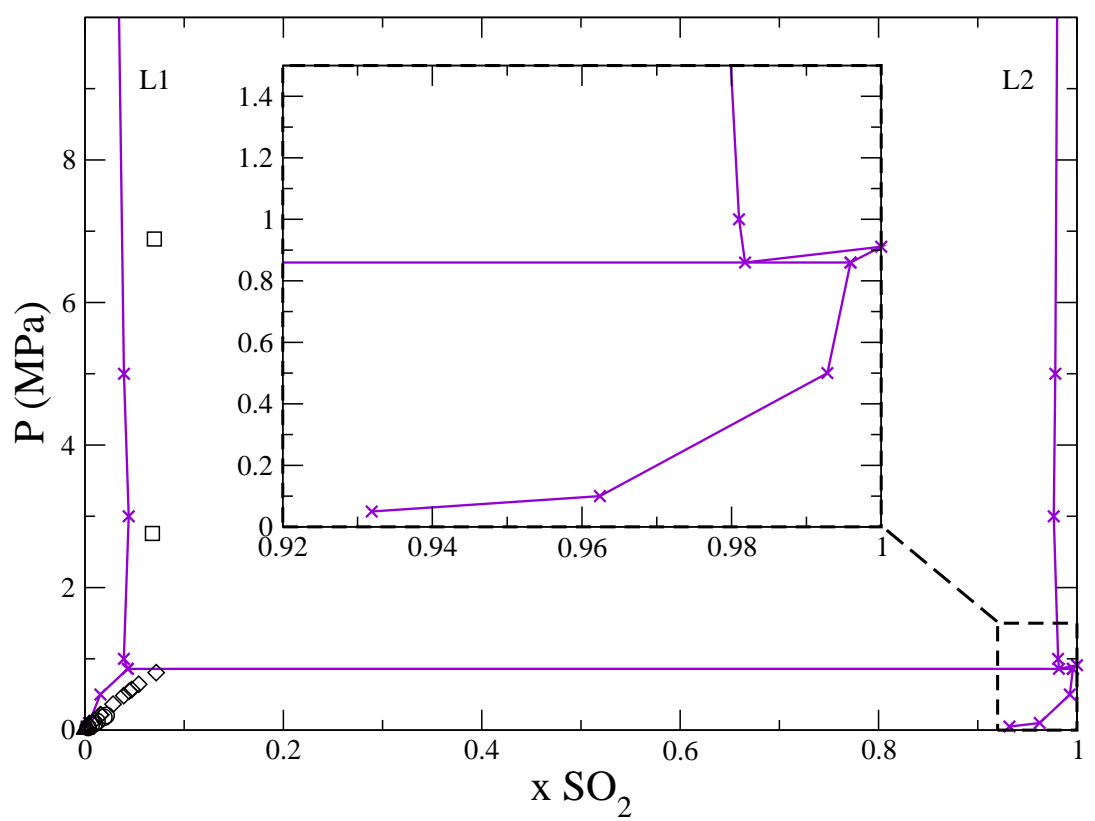

Figure 7: Phase diagrams for $\mathrm{SO}_{2}+\mathrm{H}_{2} \mathrm{O}$ binary mixtures obtained using $\mathrm{MC}$ molecular simulations at $323 \mathrm{~K}$ (crosses) for pressures up to $10 \mathrm{MPa}$, and a zoom is proposed on the $\mathrm{SO}_{2}$-rich region for pressures up to $1.5 \mathrm{MPa}$. Experimental data for the $\mathrm{H}_{2} \mathrm{O}$-rich region were extracted from works of Campbell (circles) 90], Sherwood (triangles up) 91], Rumpf (diamonds) [92] and Sayegh (squares) [93], measured at $323 \mathrm{~K}, 323 \mathrm{~K}, 333 \mathrm{~K}$, and $318 \mathrm{~K}$, respectively. 

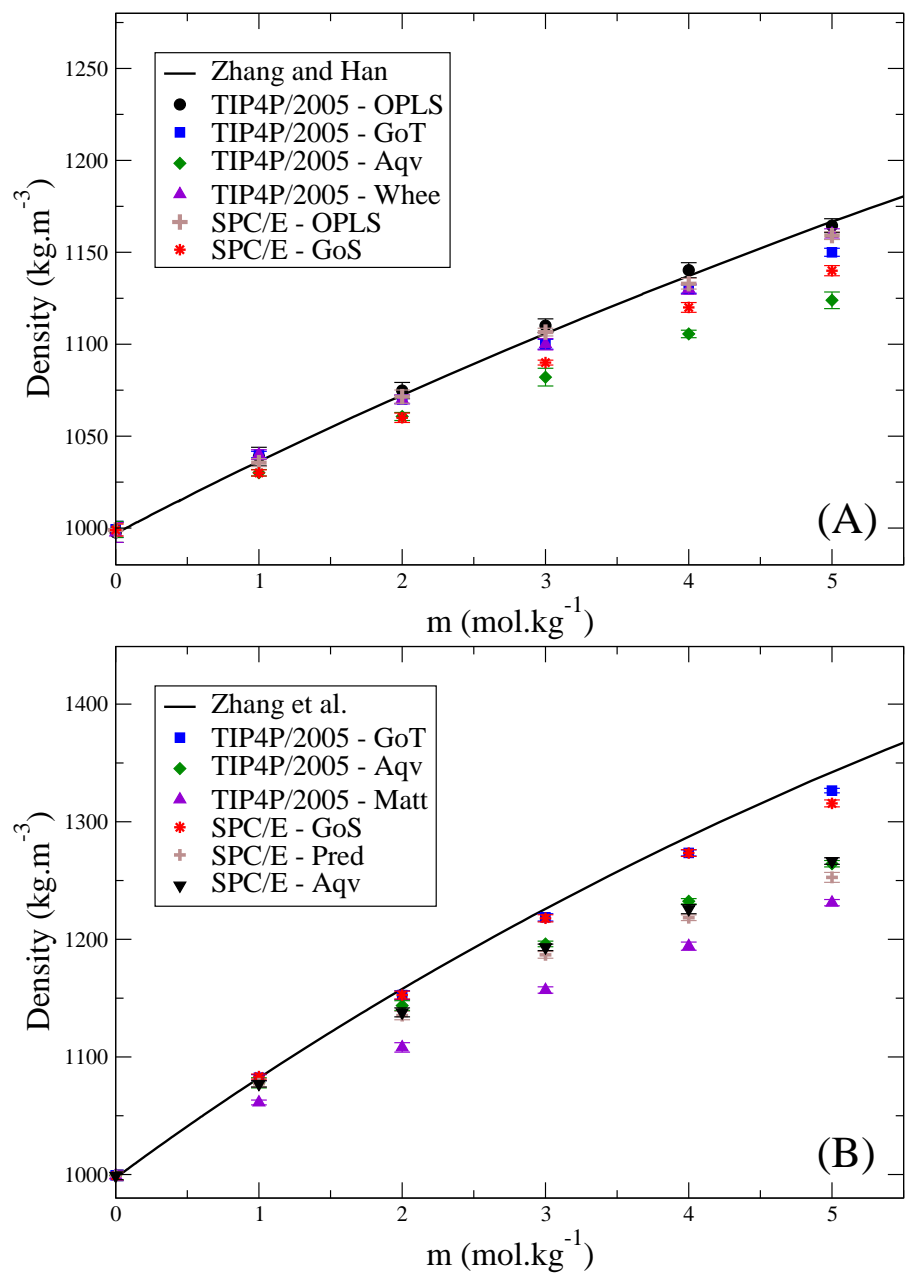

Figure 8: Predicted density values for (A) $\mathrm{NaCl}$ (see Table 12) and (B) $\mathrm{CaCl}_{2}$ (see Table 13) aqueous solutions as a function of the salt molal concentration, at $298 \mathrm{~K}$ and $0.1 \mathrm{MPa}$. The line represents experimental values extracted (A) from the work by Zhang and Han [83] and (B) from the work by Zhang et al. [94]. 

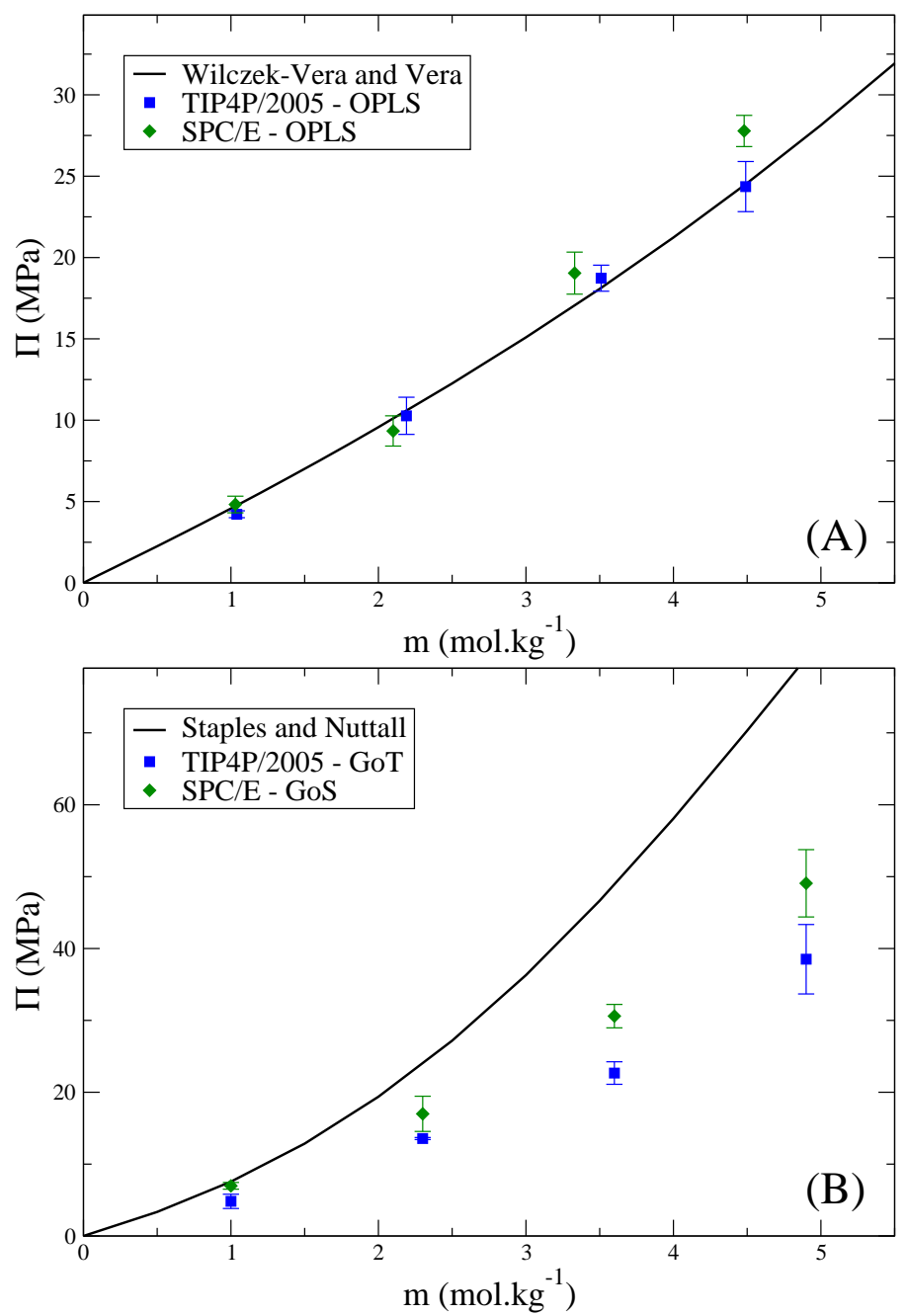

Figure 9: Comparison of experimental and predicted osmotic pressure values for (A) $\mathrm{NaCl}$ and (B) $\mathrm{CaCl}_{2}$ aqueous solutions as a function of the salt molal concentration, at $298 \mathrm{~K}$ (see values in Table 14). The line represents experimental values extracted (A) from the work by Wilczek-Vera and Vera 84 and (B) data converted from the work by Staples and Nuttall [85]. 

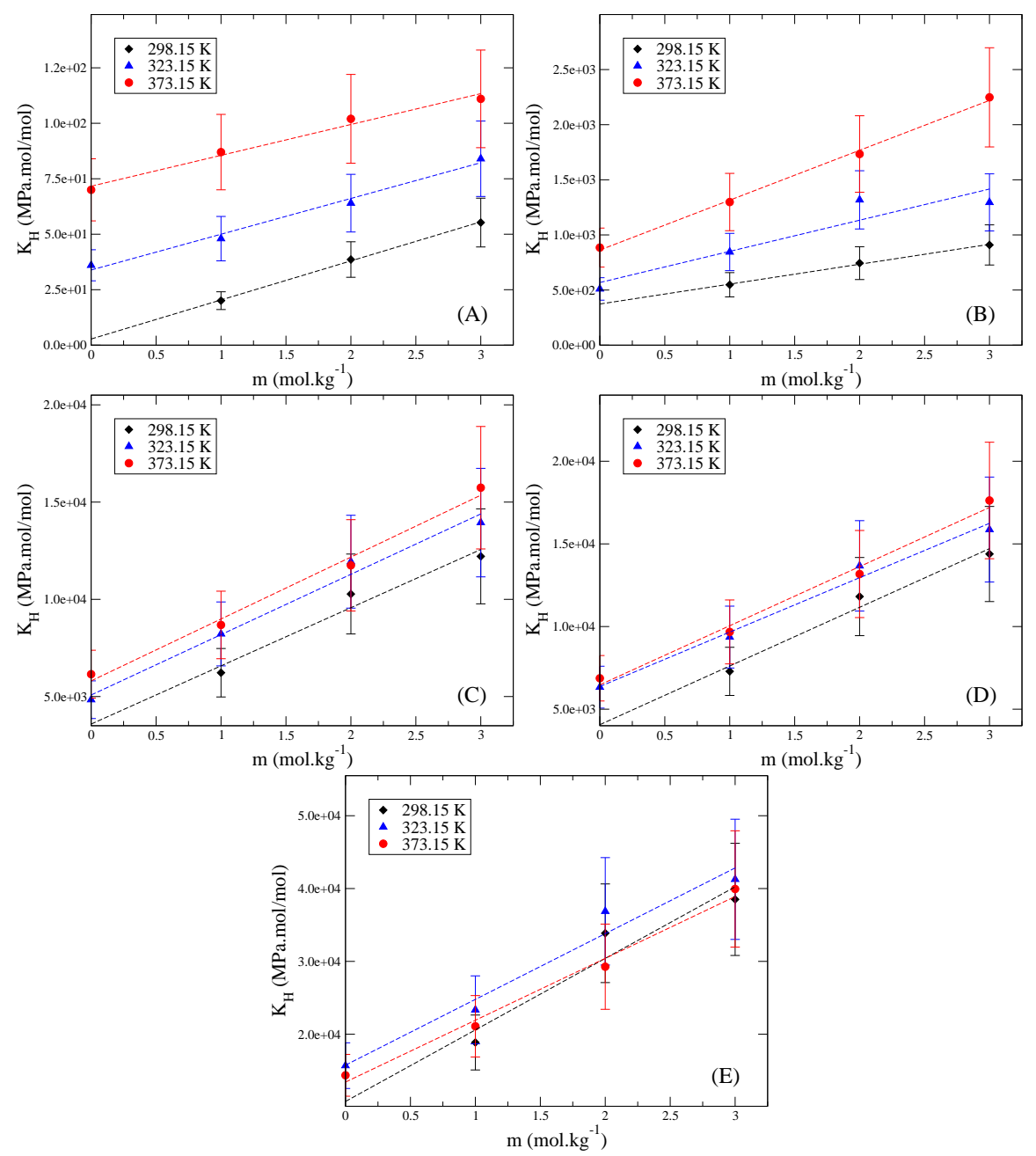

Figure 10: Simulated Henry constant values for $\mathrm{SO}_{2}$ (A), $\mathrm{CO}_{2}$ (B), $\mathrm{NO}$ (C), $\mathrm{O}_{2}$ (D), and $\mathrm{N}_{2}$ (E) in $\mathrm{NaCl}$ aqueous solutions as a function of the salt concentration, at $298.15 \mathrm{~K}$ (diamonds), $323.15 \mathrm{~K}$ (triangles) and $373.15 \mathrm{~K}$ (circles). 